\title{
Seasonal Dependence of Coupling between Storm Tracks and Sea Surface Temperature in the Southern Hemisphere Midlatitudes: A Statistical Assessment ${ }^{\mathcal{O}}$
}

\author{
Li ZHANG, BOLAN GAN, AND LIXIN WU \\ Physical Oceanography Laboratory, Cooperation and Innovation Center for Marine Science and Technology of \\ Qingdao, Ocean University of China, and Qingdao National Laboratory for Marine Science and Technology, Qingdao, China
}

WENJU CAI

Physical Oceanography Laboratory, Cooperation and Innovation Center for Marine Science and Technology of Qingdao, Ocean University of China, and Qingdao National Laboratory for Marine Science and Technology, Qingdao, China, and CSIRO Oceans and Atmosphere Flagship, Aspendale, Victoria, Australia

HAO MA

Zhejiang Climate Center, Zhejiang Meteorological Bureau, Hangzhou, China

(Manuscript received 27 March 2017, in final form 9 February 2018)

\begin{abstract}
Two-way coupling between sea surface temperature (SST) variations in the midlatitude southern oceans and changes of synoptic-scale (2-8 day) eddy activities in the lower and upper troposphere throughout the year is investigated based on lagged maximum covariance analysis using reanalysis datasets from 1951 to 2000. Results show a strong seasonal dependence of the coupling, as characterized by the most prominent one in austral midsummer (January). On one hand, SST variations in austral late spring (primarily October) are likely to influence storm tracks in the following January. That is, significant warm SST anomalies in the western midlatitude areas of South Atlantic and south Indian Ocean could result in the systematic strengthening of the low-level and upper-level eddy activities, which is presumably attributed to the coherent intensification of the SST front and the lower-tropospheric baroclinicity. Particularly, interannual variability (a spectral peak at $4 \mathrm{yr}$ ) of SST in the western midlatitude South Atlantic in October could play a predominant role in driving the corresponding variability of the Southern Hemisphere storm tracks three months later. The timing of the discernible response of storm tracks is also discussed based on the preliminary results of sensitivity experiments. On the other hand, the strengthened eddy activities in January continue to induce the dipolelike patterns of SST anomalies in the midlatitude southern oceans. Those SST response patterns are, to the first order, determined by changes of the net surface heat flux. The anomalous Ekman advections in part driven by the storm-track changes also contribute to SST anomalies in the southern subtropical South Atlantic and the western midlatitude South Pacific.
\end{abstract}

\section{Introduction}

Intense synoptic-scale transient (baroclinic) eddies prevalent in the midlatitude aloft, referred to as storm tracks in the wave dynamic perspective (Blackmon et al. 1977), play key roles in the weather and climate system. These migratory synoptic eddies are intimately related

Supplemental information related to this paper is available at the Journals Online website: https://doi.org/10.1175/JCLI-D-170196.s1.

Corresponding author: Bolan Gan, gb10203@ouc.edu.cn to active midlatitude cyclones and anticyclones, which in turn substantially affect local weather via the influence on precipitation, cloudiness, and winds (e.g., Chang et al. 2002; Field and Wood 2007). In the climate system, synoptic eddies systematically transport heat, moisture, and momentum poleward, such that they take over approximately $32 \%$ of atmospheric poleward heat transport, which accounts for about $90 \%$ of total heat transport at around $40^{\circ}$ latitude in each hemisphere (Trenberth and Caron 2001; Trenberth and Stepaniak 2003). It is also recognized that two-way interaction between synoptic eddies and large-scale mean flows is important in the formation of low-frequency climate 
modes (e.g., Lau 1988; Lorenz and Hartmann 2003; Kug et al. 2010). Therefore, prominent changes in storm tracks would considerably alter the extratropical climate.

Cayan (1992) has shown that on subyearly time scales extratropical SST anomalies (SSTAs) can be regarded as a response to atmospheric forcing. On interannualdecadal time scales, however, many modeling studies have documented the ocean-atmosphere feedback at midlatitudes, which can act as a key process to sustain lowfrequency climate variability [see Kushnir et al. (2002) for a review]. Particularly, synoptic eddies migrating along storm tracks are suggested to play a major role in regulating the equivalent barotropic response of large-scale atmospheric circulation to the extratropical SSTAs.

Over the past decade, a growing body of evidence indicates that storm tracks mutually interact with underlying oceans. Particularly over the midlatitude oceanic frontal zones, major storm tracks are found to be energized and organized along or downstream of the sharp SST gradients (Nakamura et al. 2004). For example, over the south Indian Ocean (SIO), observation shows that the zonal maxima of precipitation and poleward heat flux induced by synoptic eddies are collocated with the Antarctic polar frontal zone, which implies an important feedback of the SST front on storm tracks (Nakamura et al. 2008). Modeling studies further demonstrated that the differential sensible heat supply from the ocean across a midlatitude frontal zone is crucial for restoring the near-surface meridional temperature gradient and thus atmospheric baroclinicity, which is relaxed by the poleward heat transport by subweekly disturbances, and in turn sustains the development of storm tracks (Nakamura et al. 2008; Nonaka et al. 2009; Taguchi et al. 2009; Sampe et al. 2010; Hotta and Nakamura 2011; Ogawa et al. 2012; Small et al. 2014). Based on the idealized aquaplanet experiments, Ogawa et al. (2012) revealed the significant sensitivity of storm tracks to the latitude shift of an SST front at midlatitudes and they further pointed out the importance of the midlatitude oceanic frontal zone for the southern annular mode (SAM), the dominant mode of the midlatitude large-scale atmospheric circulation in the Southern Hemisphere (Ogawa et al. 2016). On the other hand, transport of mean westerly momentum from the subtropics by synoptic eddies acts to maintain an equivalent barotropic structure of the subpolar jet stream, also known as the polar-front jet (e.g., Palmén and Newton 1969). Such eddy-driven westerlies, collocated with the storm-track core, drive oceanic gyres and influence SST distribution through dynamical and thermodynamical processes.

Recent studies have paid more attention to the relationship between storm tracks and oceanic variations in the western boundary current regions, particularly for the Northern Hemisphere cold season. Synoptic eddies are found to covary with meridional shifts in the paths of the Gulf Stream and Kuroshio-Oyashio Extension in boreal winter (Joyce et al. 2009; Kwon and Joyce 2013), and also exhibit significant responses to the interannualdecadal variability of SST front in the Kuroshio Extension (O'Reilly and Czaja 2015; Révelard et al. 2016) and the Oyashio Extension (Smirnov et al. 2015). Gan and $\mathrm{Wu}(2013,2015)$ pointed out that SSTAs in the midlatitude North Pacific and North Atlantic, which could be driven by atmospheric variations in the first place, have significant impact on the synoptic eddy activities aloft in early winter and early spring, respectively. Overall, recent findings suggest that understanding the mutual interaction between variations of storm tracks and oceans could have active effects on the predictability improvement of the large-scale extratropical air-sea coupled mode, especially on decadal time scales (e.g., Qiu et al. 2014).

It is of great interest to investigate covariability between storm tracks and SST in the Southern Hemisphere (SH) midlatitudes, which is yet to be identified. In sharp contrast to the Northern Hemisphere (NH) storm tracks, which are intense in boreal winter, the $\mathrm{SH}$ storm tracks remain energetic throughout the year, with stronger amplitude and broader meridional profiles in austral winter (e.g., Trenberth 1991; Nakamura and Shimpo 2004; Guo et al. 2009). In terms of regional characteristics, the low-level eddy activity (see shading in Fig. 1), represented by the poleward eddy heat flux at $850 \mathrm{mb}(1 \mathrm{mb}=1 \mathrm{hPa})$, exhibits large amplitude along the polar-front jet (see contours in Fig. 1) over the South Atlantic (SA) and SIO throughout the year, whereas eddy activity over the South Pacific (SP) displays pronounced seasonality, with summertime enhancement over the south of Australia. Nakamura and Shimpo (2004) pointed out that for the SP storm tracks, the upper-level eddy activity depends largely on the seasonal march of subtropical jet, as manifested in the bifurcation into subpolar and subtropical branches, and the low-level eddy activity forms only along the polarfront jet. The greater zonal symmetry of SH storm tracks than the $\mathrm{NH}$ one allows us to examine it over a zonal sector, without being confined to a specific area. Following Gan and Wu (2015, hereinafter GW15), we investigated the seasonal coupling between SST variations in the midlatitude southern oceans and the storm-track changes throughout the year, based on the lagged maximum covariance analysis (MCA).

The rest of the paper is organized as follows. Section 2 briefly describes the datasets and statistical methods, and the lagged MCA results for the low-level and 

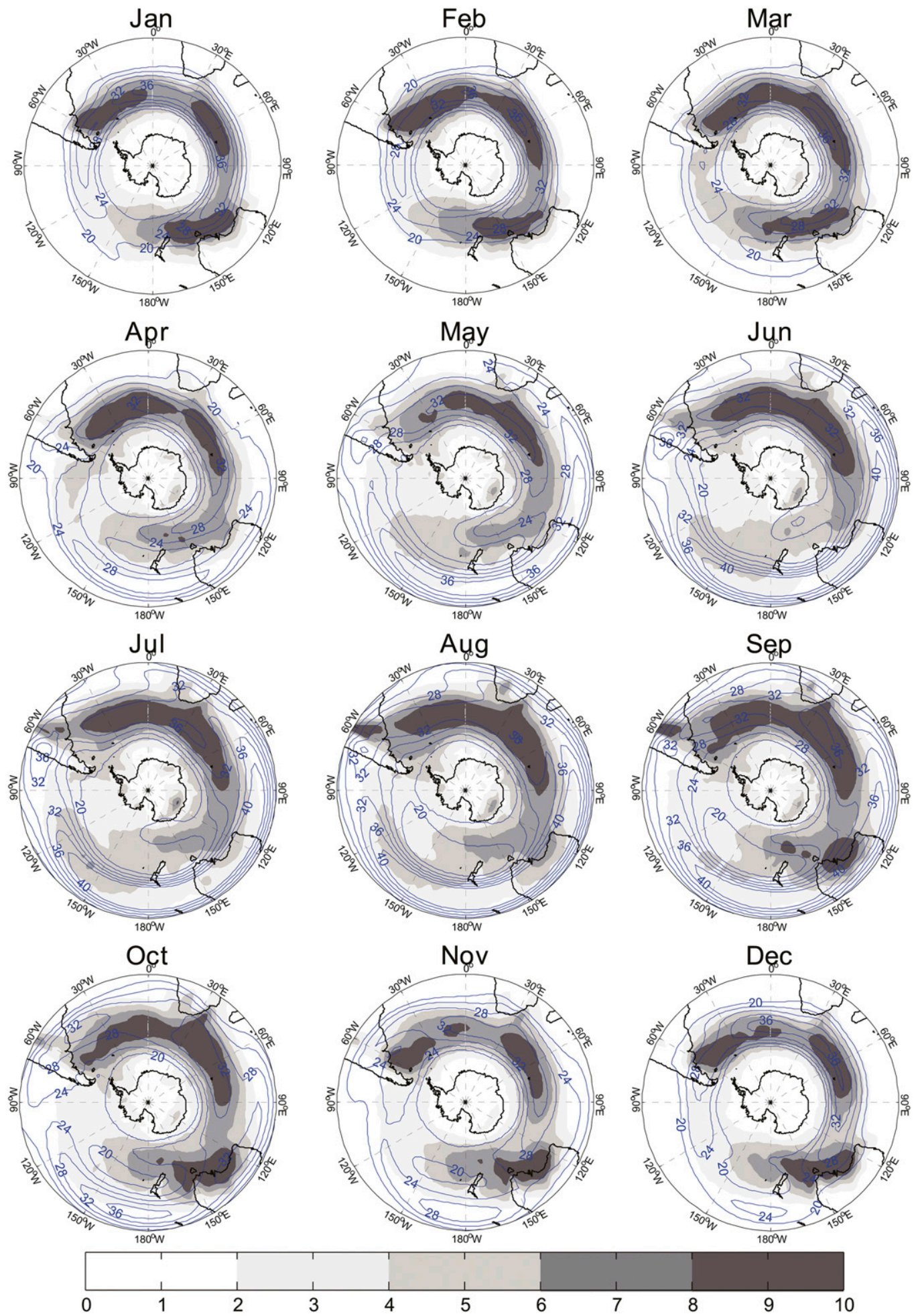

FIG. 1. Climatological-mean distribution of $850-\mathrm{mb}$ poleward heat flux associated with synoptic-scale eddies $\left\langle v^{\prime} T^{\prime}\right\rangle$ (shading; $\mathrm{K} \mathrm{m} \mathrm{s}^{-1}$ ) from January to December, superimposed on 250-mb zonal wind (blue contours) with an interval of $4 \mathrm{~m} \mathrm{~s}^{-1}$. 
upper-level storm-track activities are presented in section 3. The coupling between SST and storm-track anomalies with focus on the midsummer is investigated in sections 4 and 5. Sections 6 and 7 give a discussion and the conclusions, respectively.

\section{Datasets and methods}

Daily atmospheric fields are taken from the ensemblemean fields of the Twentieth Century Reanalysis, version $2(20 \mathrm{CRv} 2)$, with a horizontal resolution of $2^{\circ} \times 2^{\circ}$ and 24 vertical pressure levels (Compo et al. 2011). The 20CRv2 assimilates only synoptic surface pressure observations and uses observed monthly SST and sea ice concentration fields from the Met Office Hadley Centre Sea Ice and Sea Surface Temperature dataset (HadISST; Rayner et al. 2003) as prescribed boundary conditions. Given that, we used monthly SST taken from HadISST with a horizontal resolution of $1^{\circ} \times 1^{\circ}$ in the present study. Other oceanic variables including subsurface temperature and mixed layer depth are obtained from the Simple Ocean Data Assimilation (SODA) dataset (version 2.2.4) with a horizontal resolution of $0.5^{\circ} \times 0.5^{\circ}$ and 40 vertical levels (Carton and Giese 2008). All variables are analyzed in the period of 19512000 , as a compromise between better data quality in the last half century and temporal coverage that is long enough to detect significant signals. Similar results are obtained by using the HadISST and 20CRv2 data in the period of 1978-2000 and also the data taken from the National Centers for Environmental Prediction (NCEP)National Center for Atmospheric Research (NCAR) reanalysis dataset (Kalnay et al. 1996).

The low-level and upper-level storm-track activities are measured by the poleward heat flux associated with synoptic eddies at $850 \mathrm{mb}$ (i.e., the monthly covariance of 2-8-day bandpass-filtered meridional wind velocity and temperature at $850 \mathrm{mb}\left\langle v^{\prime} T^{\prime}\right\rangle$ ) and monthly variance of the 2-8-day bandpass-filtered meridional wind velocity at $250 \mathrm{mb}\left\langle v^{\prime} v^{\prime}\right\rangle$, respectively. Here a discrete Fourier transform filter is used. The poleward eddy heat flux is important in transporting the mean-flow westerly momentum downward to maintain a low-level westerly jet over the midlatitude oceanic front. Monthly anomalies are obtained by subtracting the climatological monthly means and removing influences of the longterm trend and ultralow-frequency variability based on a third-order polynomial. We also removed much of the ENSO influence by subtracting the ENSO-induced anomalous fields, which are derived from a linear regression onto the first two principal components of the tropical Pacific $\left(20^{\circ} \mathrm{S}-20^{\circ} \mathrm{N}\right)$ SSTAs in each calendar month (see GW15 for more details). Following Bretherton et al. (1999), the effective sample size, which takes into account the serial autocorrelation at lag 1 , has been used in a Student's $t$ test. The effective sample size $N_{e}$ is defined as $N_{e}=N\left(1-r_{x} r_{y}\right) /\left(1+r_{x} r_{y}\right)$, where $N$ is the length of time series and $r_{x}\left(r_{y}\right)$ is the lag-1 autocorrelation coefficient of the time series for variable $x(y)$.

The MCA isolates pairs of spatial patterns that maximize their covariance and the associated time coefficients by performing a singular value decomposition of the covariance matrix between two fields. The statistical significance of MCA metric [i.e., squared covariance (SC), squared covariance fraction (SCF), and correlation coefficient (CO) between MCA time coefficients] is tested based on the Monte Carlo test. Specifically, by using the original SSTAs and the anomalous storm-track field with the time series randomly scrambled, we repeated the MCA for 100 times and then obtained 100 metrics, whose probability distribution function is constructed to rank the confidence level of the actual statistic. In the present study, the homogeneous map for SST and the heterogeneous map for storm tracks, which are projections onto the SST time coefficients of the MCA mode with SST leading storm tracks, are shown to illustrate the influence of SSTAs on the storm-track activity. Likewise, the heterogeneous map for SST and the homogeneous map for storm tracks, derived from the MCA mode with storm tracks leading SST, are shown to illustrate the oceanic response to the storm-track variations.

In the present study, we also diagnosed the dry baroclinic instability of atmosphere and the local baroclinic energy conversion (BCEC) associated with the subweekly disturbances. The dry baroclinicity is measured by the Eady growth rate (Lindzen and Farrell 1980), that is, $\sigma_{\text {Eady }}=0.31 g(N \bar{\theta})^{-1}|\partial \bar{\theta} / \partial y|$, where $N$ denotes the BruntVäisälä frequency given by $N^{2}=-\rho g^{2} \bar{\theta}^{-1}(\partial \theta / \partial p)$, $\rho=P R_{d}^{-1} \bar{\theta}^{-1}\left(P_{0} / P\right)^{R_{d} / C_{p}}, P_{0}=1000 \mathrm{mb}, \bar{\theta}$ is the average of monthly mean potential temperature between two adjacent pressure levels, and the other notation is standard. The BCEC from mean available potential energy (MAPE) to eddy available potential energy (EAPE) and from EAPE to eddy kinetic energy (EKE) are defined as follows (Cai et al. 2007):

$$
\begin{aligned}
& \text { BCEC (from MAPE to EAPE) } \\
& \quad=-C_{1}\left(\frac{P_{0}}{P}\right)^{R_{d} / C_{p}}\left(-\frac{d \theta}{d p}\right)^{-1}\left(\overline{u^{\prime} T^{\prime}} \frac{\partial \bar{T}}{\partial x}+\overline{v^{\prime} T^{\prime}} \frac{\partial \bar{T}}{\partial y}\right) \text { and }
\end{aligned}
$$

$\mathrm{BCEC}($ from EAPE to EKE $)=-C_{1} \overline{w^{\prime} T^{\prime}}$,

where $C_{1}=\left(P_{0} / P\right)^{C_{v} / C_{p}} R_{d} / g ; u$ and $v$ are the zonal and meridional wind velocity, respectively, and $w$ is vertical velocity in pressure coordinates; and the other notation 
is standard. The overbar signifies time average, and the prime denotes the synoptic-scale transients.

\section{Lagged MCA results for the lower and upper troposphere}

To look into the coupling between SST in the midlatitude southern oceans and the low-level and upperlevel storm-track activities throughout the year, the MCA is applied as a function of time lag in month for monthly anomalies of SST and 850-mb $\left\langle v^{\prime} T^{\prime}\right\rangle$ (250-mb $\left.\left\langle v^{\prime} v^{\prime}\right\rangle\right)$ in the SH midlatitudes $\left(30^{\circ}-60^{\circ} \mathrm{S}\right.$ and all longitudes). Considering that synoptic eddy anomalies hardly persist into the next month, we performed the MCA with a single month per year (i.e., $\left\langle v^{\prime} T^{\prime}\right\rangle$ and $\left\langle v^{\prime} v^{\prime}\right\rangle$ anomalies are fixed in a calendar month, with SSTAs leading or following by month). The MCA results are summarized in Fig. 2 for the first MCA modes between lag -5 month (SST leads) and lag +5 month (SST follows). Note that no significant influence of SSTAs on storm tracks is found in the second MCA modes.

It can clearly be seen that the $\mathrm{SC}, \mathrm{SCF}$, and $\mathrm{CO}$ for both $\left\langle v^{\prime} T^{\prime}\right\rangle$ and $\left\langle\boldsymbol{v}^{\prime} \boldsymbol{v}^{\prime}\right\rangle$ are coherently characterized by a pronounced seasonal dependence and an asymmetry of time lag. When storm tracks lead SST, both SC and SCF show the highest significance in January, June, and July, with maxima at lag +1 month in January (the maximum SCF of $40 \%$ for $\left\langle\boldsymbol{v}^{\prime} T^{\prime}\right\rangle$ and $48 \%$ for $\left.\left\langle\boldsymbol{v}^{\prime} \boldsymbol{v}^{\prime}\right\rangle\right)$. However, as for SST leading, the most significant and maximum SC (SCF) appears when $\left\langle v^{\prime} T^{\prime}\right\rangle$ and $\left\langle v^{\prime} v^{\prime}\right\rangle$ anomalies are taken in January, and the SSTA precedes by 3 months. The maximum SCF at lag -3 month is $41 \%$ for $\left\langle v^{\prime} T^{\prime}\right\rangle$ and $50 \%$ for $\left\langle\boldsymbol{v}^{\prime} \boldsymbol{v}^{\prime}\right\rangle$. Although the SC and SCF for the MCA modes with $\left\langle\boldsymbol{v}^{\prime} \boldsymbol{v}^{\prime}\right\rangle$ taken in June display high significance between lag -5 and lag -1 month, there are no consistent signatures for $\left\langle v^{\prime} T^{\prime}\right\rangle$. Therefore, the MCA results suggest that the coupling between storm tracks and SST in the SH midlatitudes is most prominent in midsummer (January). Specifically, SSTAs in the preceding late spring (primarily October) are likely to influence both the low-level and upper-level eddy activities in January, which continues to drive SST variations.

\section{Influence of SST on the storm-track activity in midsummer}

The coupling between SST and $\left\langle v^{\prime} T^{\prime}\right\rangle$ in midsummer is illustrated in Fig. 3, which shows the maximum covariance patterns corresponding to the first MCA modes with $\left\langle v^{\prime} T^{\prime}\right\rangle$ fixed in January and SST in the preceding October-December and in the following February. When SST leads $\left\langle v^{\prime} T^{\prime}\right\rangle$ by up to 3 months, the SST anomaly pattern in October (colors in Fig. 3a) exhibits large warm anomalies in the western midlatitude areas of SA, SIO, and SP, with the maximum of $0.52^{\circ} \mathrm{C}$ off the Atlantic coast of Argentina. Such warm SSTAs are persistent to December and become predominant in the southern oceans (Figs. 3b,c). The SST time coefficients in October is indeed correlated with the one in November and December, with the correlation of 0.74 and 0.57 (significant at the $95 \%$ confidence level), respectively. In association with SSTAs in the preceding October, the $\left\langle v^{\prime} T^{\prime}\right\rangle$ anomaly pattern in January (contours in Fig. 3a) displays two centers of positive anomalies, which are located over the poleward flank of warm SSTAs in the western areas of SA and SIO. Given the spatial distribution of the climatological $\left\langle v^{\prime} T^{\prime}\right\rangle$ in January (Fig. 1), the anomaly $\left\langle v^{\prime} T^{\prime}\right\rangle$ pattern indicates a strengthening of the low-level eddy activity. Indeed, comparing with the maximum covariance patterns of $\left\langle v^{\prime} T^{\prime}\right\rangle$ in November (December) related to the preceding SSTAs at lag $-1(\mathrm{lag}-2)$ month (see Fig. S1 in the supplemental material; noting that the corresponding MCA metric is statistically insignificant as shown in Fig. 2), the response of $\left\langle v^{\prime} T^{\prime}\right\rangle$ in January is unique and can be physically understandable (see the following text). The corresponding time coefficients of SST and $\left\langle v^{\prime} T^{\prime}\right\rangle$ exhibit a coherent interannual variability, with the correlation of 0.73 , which, however, has no statistically significant relationship with the SAM index in January [Fig. 4a; the correlation between SST $\left(\left\langle v^{\prime} T^{\prime}\right\rangle\right)$ time coefficients and the January SAM index is $0.17(0.22)]$.

We also examined the maximum covariance patterns corresponding to the first MCA mode between $\left\langle\boldsymbol{v}^{\prime} \boldsymbol{v}^{\prime}\right\rangle$ in January and SST in the preceding October (Fig. 5b). It can clearly be seen that the $\left\langle\boldsymbol{v}^{\prime} \boldsymbol{v}^{\prime}\right\rangle$ response pattern, with significant positive anomalies extending from the western SA to the western SP, also illustrates a strengthening of $\left\langle\boldsymbol{v}^{\prime} \boldsymbol{v}^{\prime}\right\rangle$ relative to its climatology (Fig. 5a). Overall, SST variations in late spring (primarily October) are likely to influence storm tracks in the following midsummer (January), which is manifested as a systematic strengthening of both the low-level and upper-level eddy activities in response to warm SSTAs in the western areas of the southern oceans at the midlatitudes. Note that given a great similarity of the MCA results for $\left\langle v^{\prime} T^{\prime}\right\rangle$ and $\left\langle v^{\prime} v^{\prime}\right\rangle$, we primarily focused on the $\left\langle v^{\prime} T^{\prime}\right\rangle$ in the following examinations.

A question then arises as to which center of the SST anomaly pattern in October has the strongest influence on storm tracks. To shed some light on this question, we regressed $\left\langle v^{\prime} T^{\prime}\right\rangle$ anomalies in January onto three SST time series in the preceding October, which are derived from the area-averaged SSTAs in three boxes covering the main centers of warm SSTAs. Boxes are bounded by 

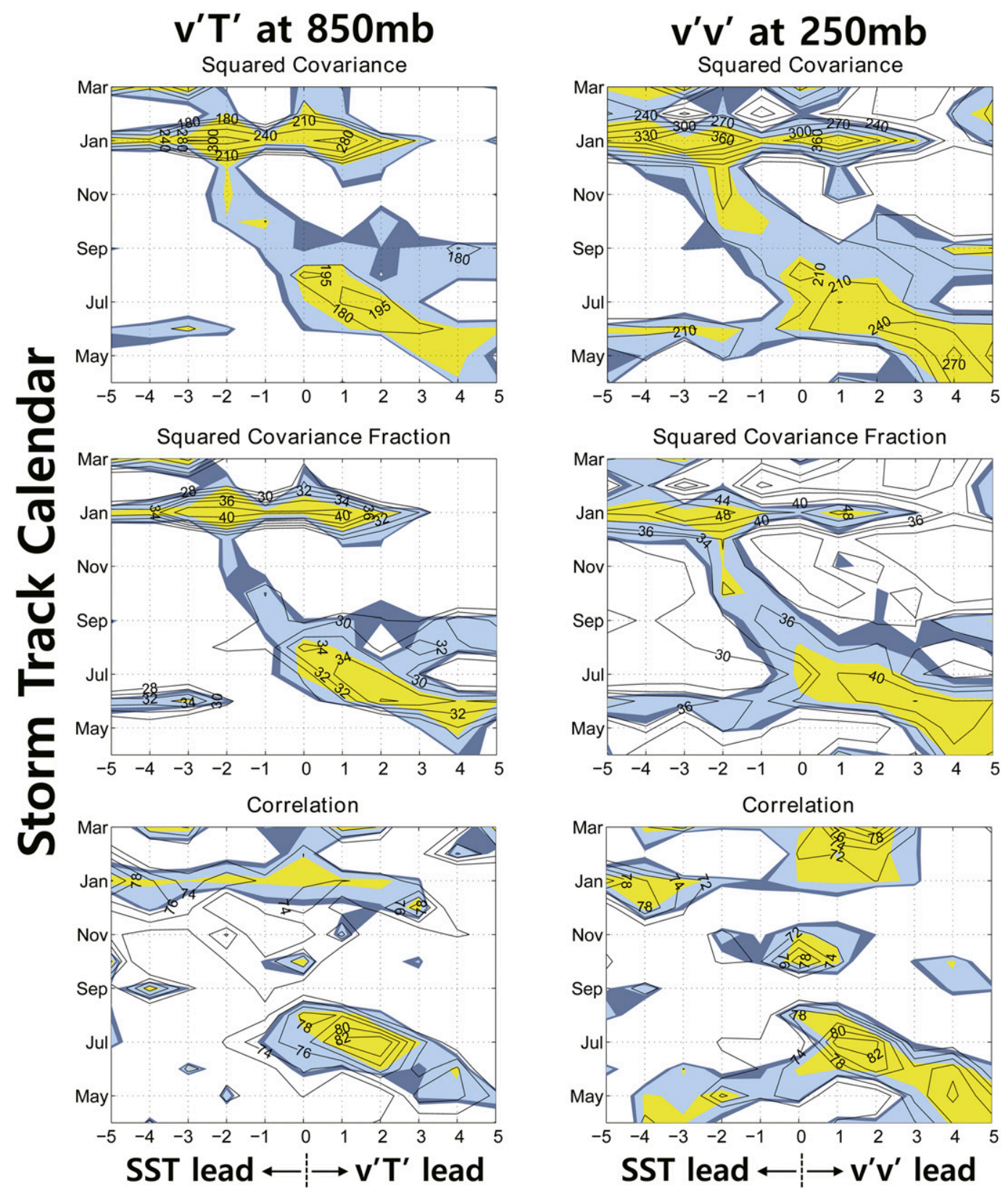

FIG. 2. (top)-(bottom) SC $\left(10^{2}\right)$, SCF $\left(10^{-2}\right)$, and CO $\left(10^{-2}\right)$ of the first MCA mode between SST and storm tracks represented by (left) $850-\mathrm{mb}\left\langle\boldsymbol{v}^{\prime} T^{\prime}\right\rangle$ and (right) $250-\mathrm{mb}\left\langle\boldsymbol{v}^{\prime} \boldsymbol{v}^{\prime}\right\rangle$ in the SH midlatitudes. SCs are dimensionless as SST and storm-track fields have been normalized. Values with $\mathrm{SC} \geq 18000, \mathrm{SCF} \geq 0.28$, and $\mathrm{CO} \geq 0.72$ are plotted. Shading indicates statistical significance at the $85 \%$ (dark blue), $90 \%$ (light blue), and $95 \%$ (yellow) confidence level based on the Monte Carlo test. Ordinate is the calendar month of storm tracks, and abscissa is the time lag in month, with positive (negative) for storm tracks (SST) leading SST (storm tracks).

$32^{\circ}-55^{\circ} \mathrm{S}, 30^{\circ}-70^{\circ} \mathrm{W} ; 30^{\circ}-50^{\circ} \mathrm{S}, 30^{\circ}-75^{\circ} \mathrm{E}$; and $30^{\circ}-60^{\circ} \mathrm{S}$, $150^{\circ} \mathrm{E}-160^{\circ} \mathrm{W}$ in the western midlatitude areas of SA, SIO, and SP, respectively (see boxes in Fig. 3a for reference). As shown in Fig. $6 \mathrm{a}$, the $\left\langle v^{\prime} T^{\prime}\right\rangle$ regression pattern associated with the warm SSTA centers in the SA highly resembles the corresponding MCA pattern (contours in Fig. 3a), with the spatial correlation of 0.80 .
However, the $\left\langle v^{\prime} T^{\prime}\right\rangle$ regression patterns associated with the warm SSTA centers in the SIO (Fig. 6b) and the SP (Fig. 6c) bear less resemblance, with the spatial correlation of 0.58 and 0.32 , respectively. It should be noted that the statistically significant regressions of the SIO storm tracks against the SP SSTAs are likely to reflect the significant correlation between the time series of 
(a)Lag=-3mo(SST-Oct/v'T'-Jan)

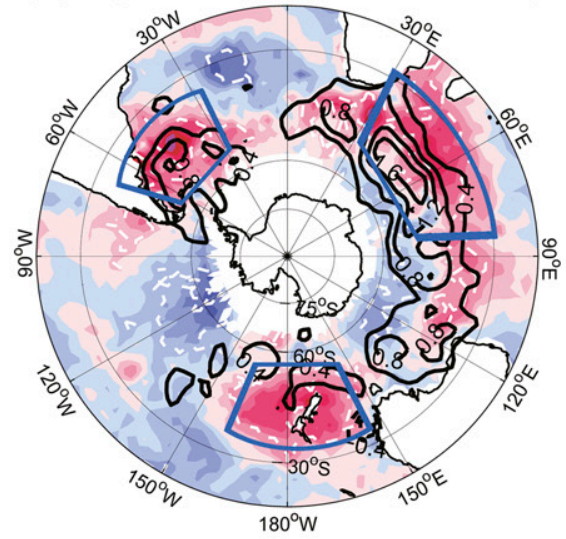

(b)Lag=-2mo(SST-Nov/v'T'-Jan)

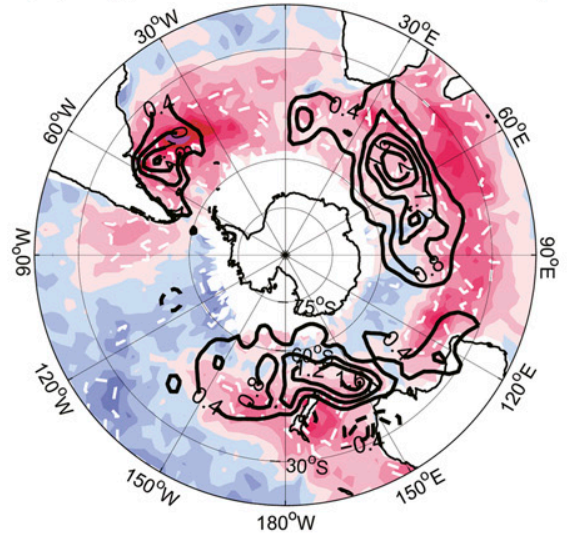

(c)Lag=-1 mo(SST-Dec/v'T'-Jan)

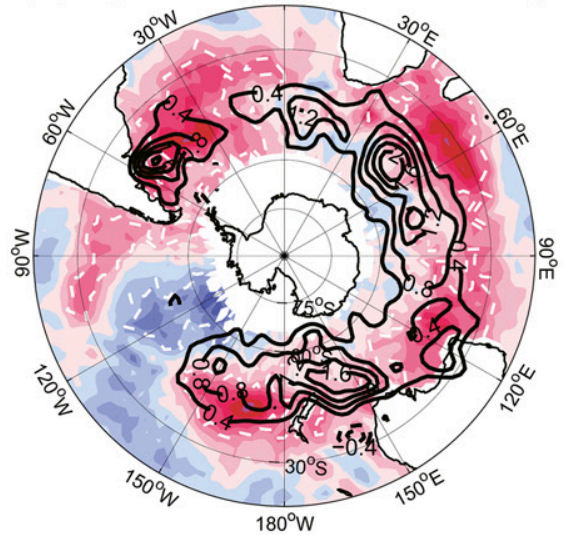

(d)Lag=0mo(SST-Jan $\left./ v^{\prime} T^{\prime}-J a n\right)$

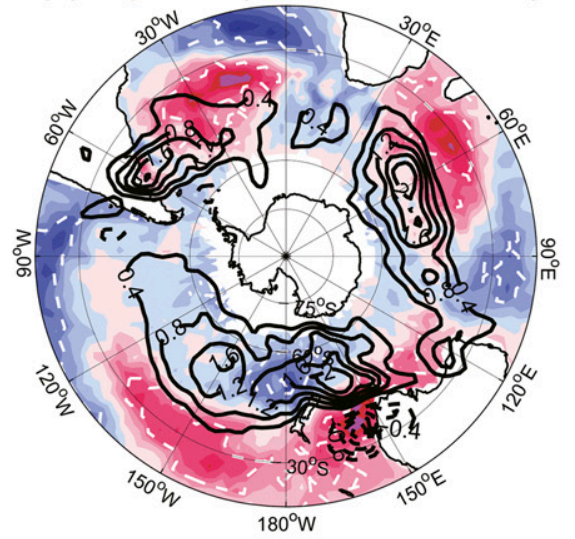

(e)Lag=1mo(SST-Feb/v'T'-Jan)

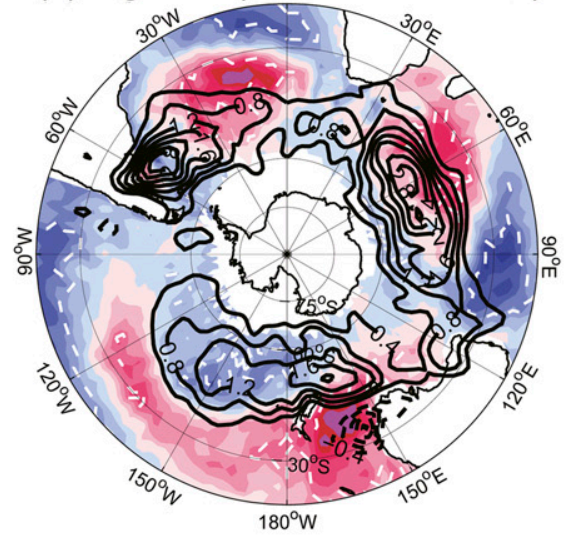

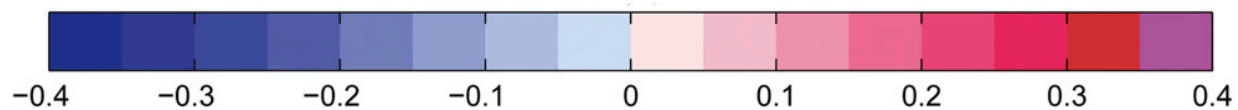

FIG. 3. Homogeneous maps for SST and heterogeneous maps for 850-mb $\left\langle v^{\prime} T^{\prime}\right\rangle$ corresponding to the first MCA modes with $\left\langle v^{\prime} T^{\prime}\right\rangle$ fixed in January and SST leading by (a)-(c) from 3 to 1 month. (d) Simultaneously heterogeneous maps for SST and $\left\langle v^{\prime} T^{\prime}\right\rangle$ in January. (e) As in (a), but for the heterogeneous map for SST and homogeneous map for $\left\langle v^{\prime} T^{\prime}\right\rangle$ leading by 1 month. Color shading is SST $\left({ }^{\circ} \mathrm{C}\right)$ and contours are for $\left\langle v^{\prime} T^{\prime}\right\rangle\left(\mathrm{K} \mathrm{m} \mathrm{s}^{-1}\right)$ with negative values dashed and an interval of $0.4 \mathrm{~K} \mathrm{~m} \mathrm{~s}^{-1}$. All plotted contours and dashed white lines for $\left\langle v^{\prime} T^{\prime}\right\rangle$ and shaded areas of SSTAs are significant at the $95 \%$ confidence level, respectively. The MCA time coefficients have been normalized so that the typical amplitudes are given. The SA, SIO, and SP regions are outlined in (a). 
(a) Lag=-3mo (SST-Oct/v'T'-Jan)

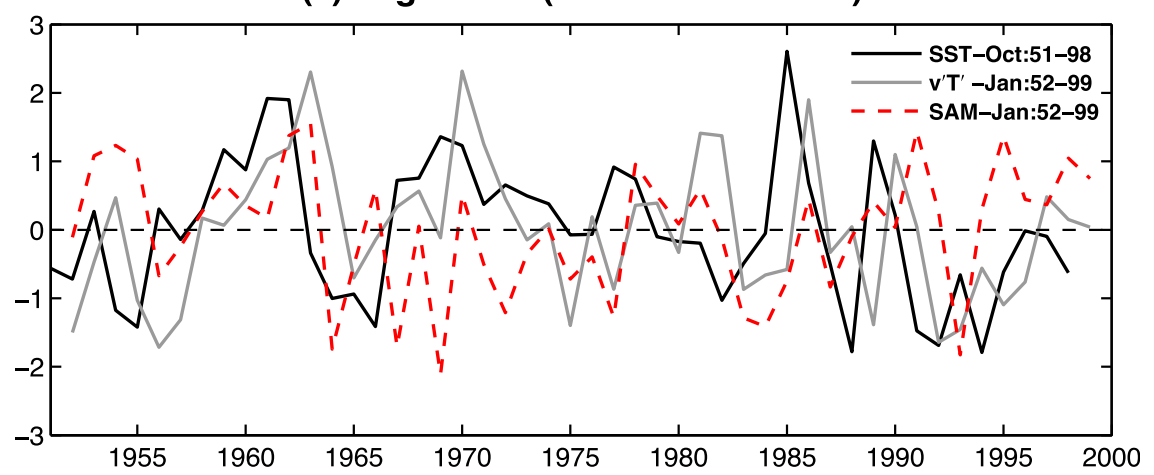

(b) Lag=1mo (SST-Feb/v'T'-Jan)

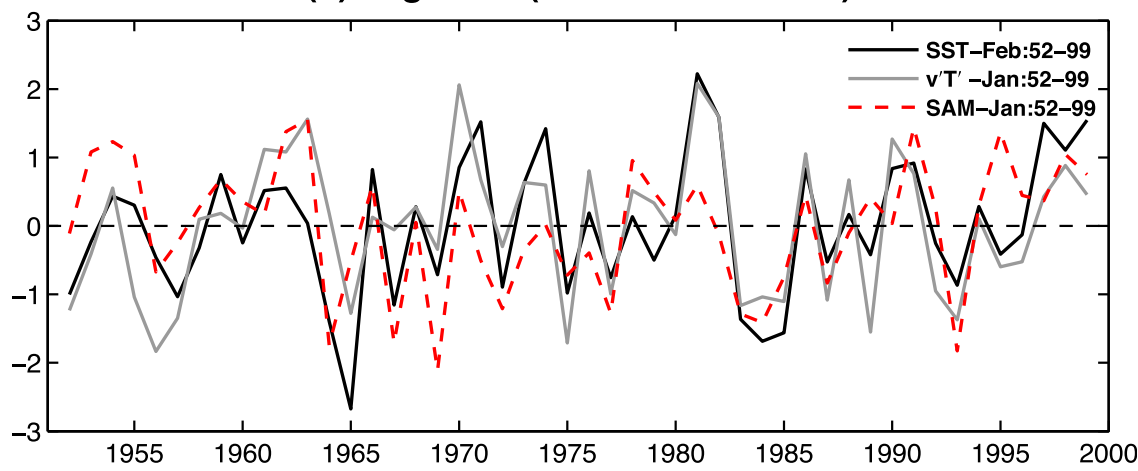

FIG. 4. Normalized time coefficients of $\left\langle v^{\prime} T^{\prime}\right\rangle$ (gray line) in January and SST (black line) lagging by (a) -3 and (b) +1 month derived from the corresponding first MCA modes, together with the SAM index in January (red dashed line). The SAM index is defined as the difference in the normalized monthly zonal-mean sea level pressure between $40^{\circ}$ and $70^{\circ} \mathrm{S}$ ( $\mathrm{Nan}$ and $\mathrm{Li} 2003$ ). Here the positive anomaly of the SAM index corresponds to the positive phase of SAM [i.e., band of westerly winds contracts toward Antarctica (see Fig. S2 in the supplemental material)].

SSTAs in the SP and SA/SIO [i.e., $r(\mathrm{SA}, \mathrm{SP})=0.52$ and $r$ $(\mathrm{SIO}, \mathrm{SP})=0.37]$, which cannot be interpreted as the remote influence of the SP SSTAs on the upstream storm tracks. We also did the similar lagged regression analysis but by using three SST time series in the preceding November. The $\left\langle v^{\prime} T^{\prime}\right\rangle$ regression patterns associated with the SA and SIO SSTAs in November (Figs. 6d,e) generally bear some similarity to those in Figs. 6a,b, albeit with the higher regression coefficients in Fig. 6e. However, the regressions of $\left\langle v^{\prime} T^{\prime}\right\rangle$ associated (a) $250 \mathrm{mb} v^{\prime} v^{\prime}($ Jan $)$

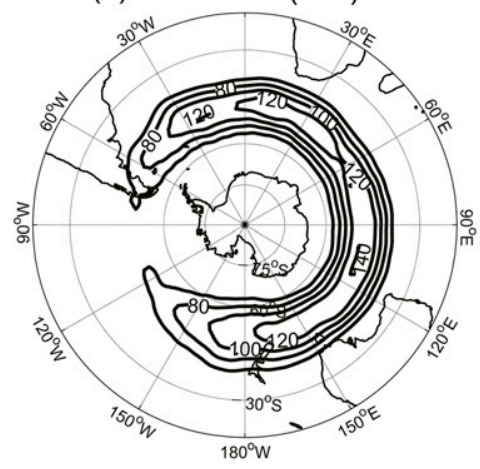

(b) Lag $=-3 \mathrm{mo}\left(\mathrm{SST}-\mathrm{Oct} / \mathrm{v}^{\prime} \mathrm{v}^{\prime}-\mathrm{Jan}\right)$

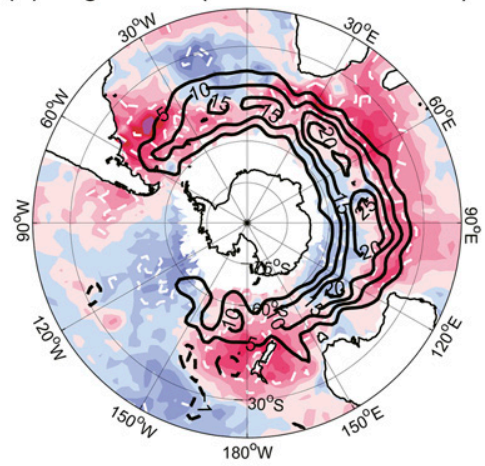

(c) Lag $=1 \mathrm{mo}\left(\mathrm{SST}-\mathrm{Feb} / \mathrm{v}^{\prime} \mathrm{v}^{\prime}-\mathrm{Jan}\right)$

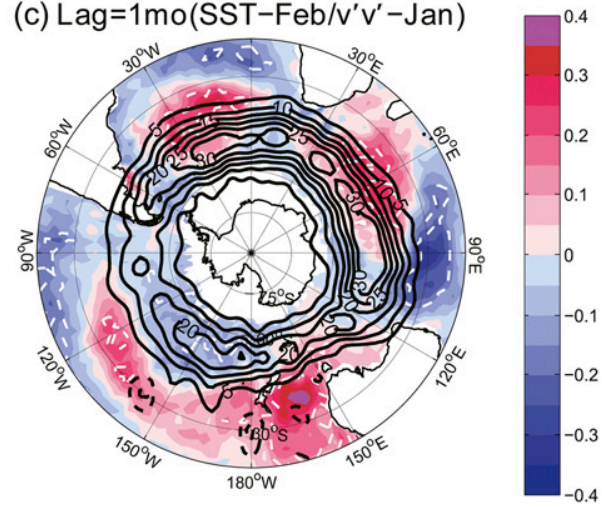

FIG. 5. (a) Climatological-mean distribution of 250-mb $\left\langle v^{\prime} v^{\prime}\right\rangle\left(\mathrm{m}^{2} \mathrm{~s}^{-2}\right)$ in January. (b),(c) As in Figs. 3a,e, but for the first MCA mode between $\left\langle v^{\prime} v^{\prime}\right\rangle$ in January and SST in the preceding October or in the following February, respectively. 
(a) South Atlantic-Oct

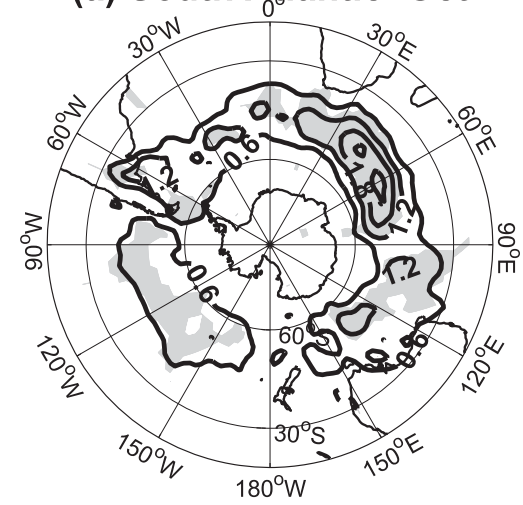

(d) South Atlantic-Nov

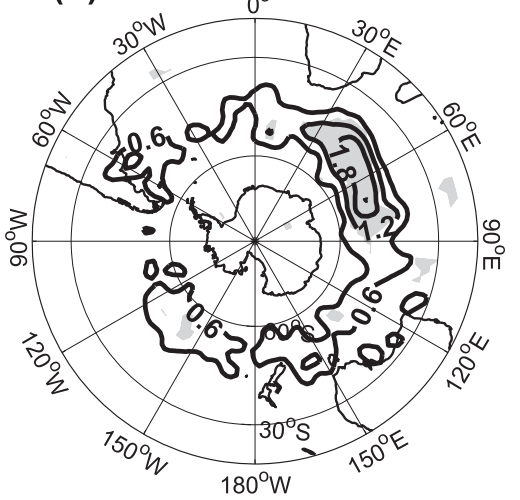

(b) South Indiąn Ocean-Oct

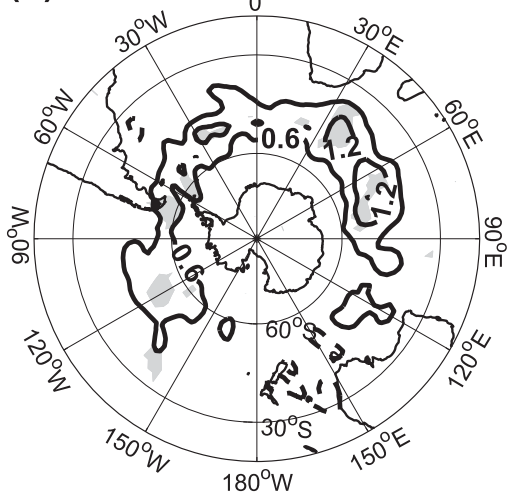

(e) South Indian Ocean-Nov

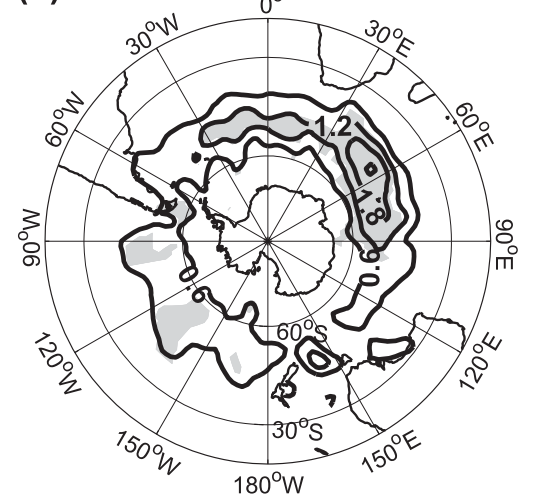

(c) South Pacific-Oct

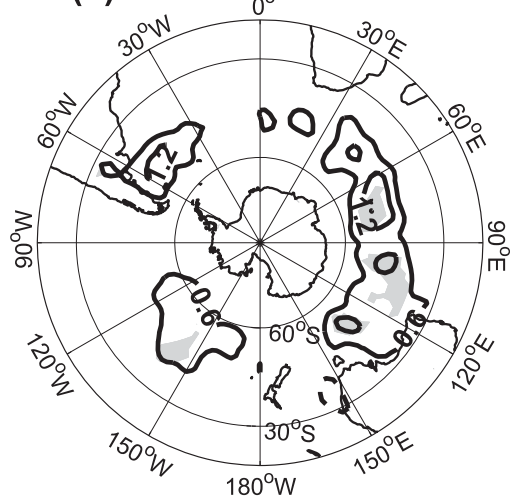

(f) South Pacific-Nov

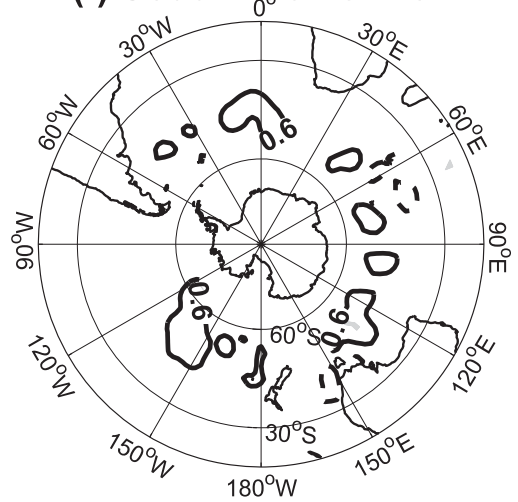

FIG. 6. Lagged regression of $\left\langle v^{\prime} T^{\prime}\right\rangle$ anomalies in January associated with the centers of warm SSTAs in (a) the SA, (b) the SIO, and (c) the SP in the preceding October (see text and boxes in Fig. 3a). (d)-(f) As in (a)-(c), but for the centers of warm SSTAs in the preceding November. The contour interval is $0.6 \mathrm{~K} \mathrm{~m} \mathrm{~s}^{-1}$. Shaded areas denote regressions significant at the $99 \%$ confidence level.

with the SP SSTAs in November have nearly vanished, which confirms the less importance of SSTAs in the western midlatitude SP than the other two areas in affecting storm tracks. In general, results suggest that SSTAs in the western midlatitude SA in October could play a predominant role in affecting the SH storm tracks in the following January. Given the independence of the above analysis from the MCA, it is also suggested that the MCA results are robust.

How do the SST variations in the midlatitude southern oceans affect storm tracks? A physical link lies in the changes of surface turbulent heat flux (latent plus sensible heat flux) associated with the SST forcing. As suggested by Gastineau and Frankignoul (2012), a statistical estimate of the surface turbulent heat flux anomalies associated with the preceding SST variations (referred to as $Q_{\text {turb }}$ ) could be a mixture of the heat flux response induced by the oceanic change (referred to as $\left.Q_{\text {ocean }}\right)$ and a fast response of heat flux that is an imprint of atmospheric response to the boundary condition change (referred to as $Q_{\text {atmos }}$ ). Here we estimated
$Q_{\text {atmos }}$ by the following procedures: 1$)$ regress the sea level pressure (SLP) anomaly field with a time lag against the SST time coefficients in October taken from the MCA mode at lag -3 month to obtain the lagged regression coefficients of SLP anomaly (see Fig. S3 in the supplemental material), 2) project the same SLP anomaly field onto such regression coefficients to obtain the expansion coefficients of SLP anomaly that is regarded as a reflection of the large-scale atmospheric response, and 3) simultaneously regress the anomaly field of surface turbulent heat flux against the corresponding expansion coefficients of the SLP anomaly to obtain $Q_{\text {atmos }}$. Then, $Q_{\text {turb }}$ is obtained by the lagged regression of surface turbulent heat flux against the SST time coefficients in October, and $Q_{\text {ocean }}$ is obtained as a residual by $Q_{\text {ocean }}=Q_{\text {turb }}-Q_{\text {atmos }}$.

Figure 7 illustrates the changes of surface turbulent heat flux $Q_{\text {turb }}$ in November, December, and January related to the SST variations in October, as well as their two components $\left(Q_{\text {atmos }}\right.$ and $\left.Q_{\text {ocean }}\right)$. In November, there are significant upward $Q_{\text {turb }}$ anomalies (dominated 
(a) Q-turbulent (Nov)

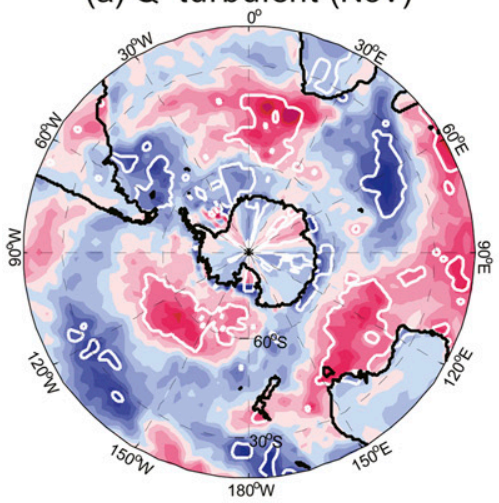

(d) Q-atmosphere (Nov)

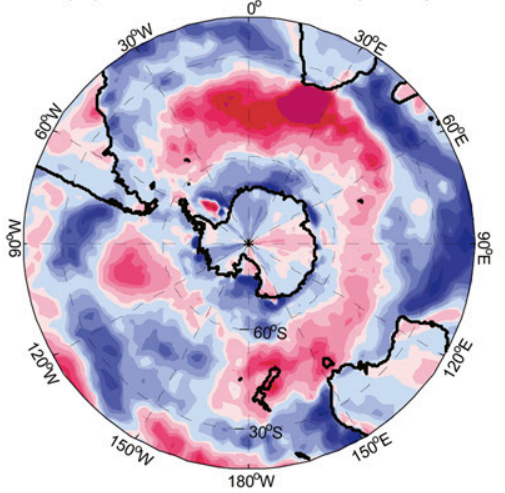

(g) Q-ocean (Nov)

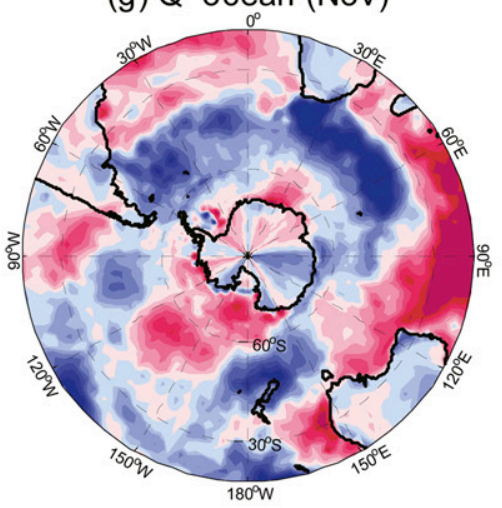

(b) Q-turbulent (Dec)

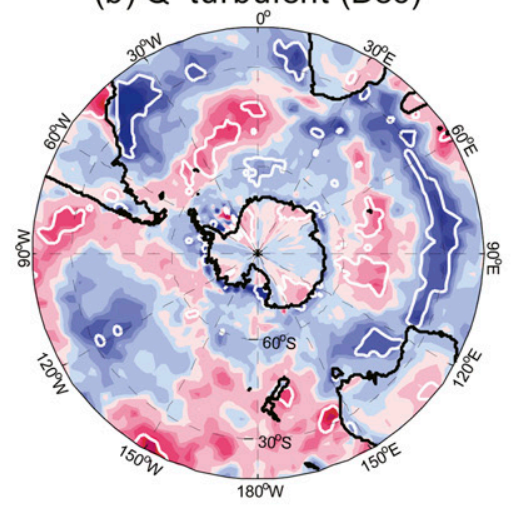

(e) Q-atmosphere (Dec)

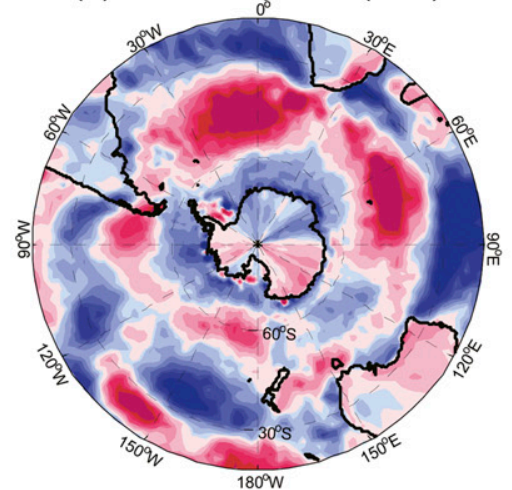

(h) Q-ocean (Dec)

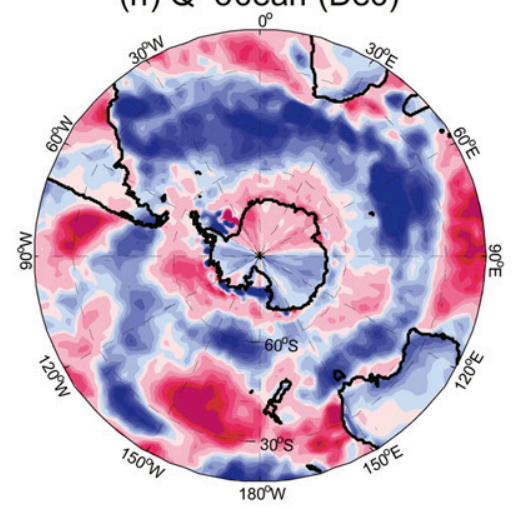

(c) Q-turbulent (Jan)

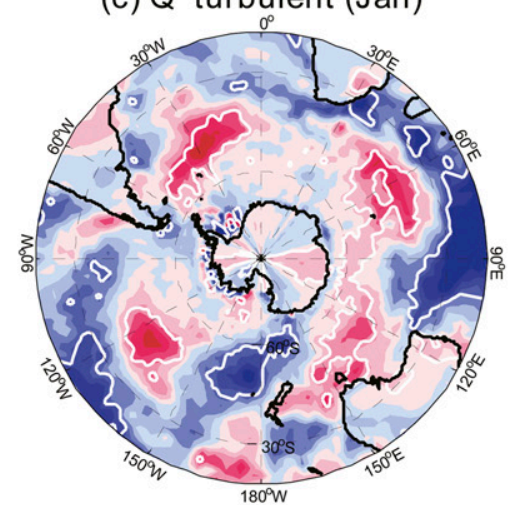

(f) Q-atmosphere (Jan)

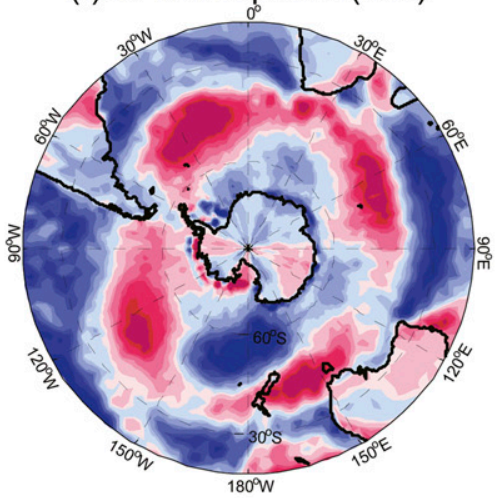

(i) Q-ocean (Jan)

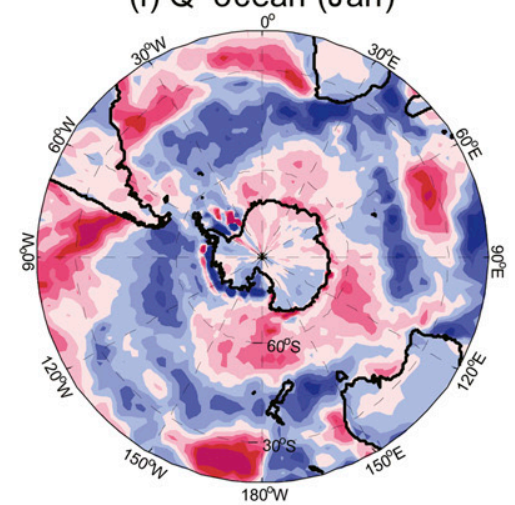

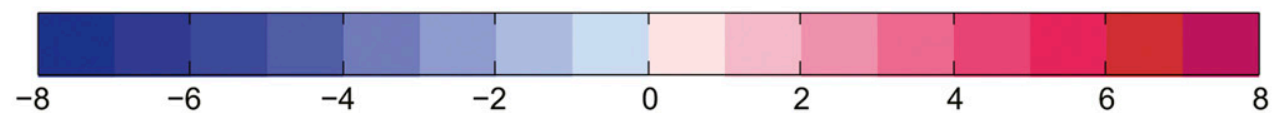

FIG. 7. Lagged regression of $Q_{\text {turb }}$ (negative upward; $\mathrm{W} \mathrm{m}^{-2}$ ) in (a) November, (b) December, and (c) January against the SST time coefficients in October at lag -3 month. The corresponding surface turbulent heat flux anomalies induced by (d)-(f) $Q_{\text {atmos }}$ and (g)-(i) $Q_{\text {ocean }}$, which are related to the SST variations in October. Here, $Q_{\text {ocean }}=Q_{\text {turb }}-Q_{\text {atmos. }}$. White contours denote regressions significant at the $90 \%$ confidence level.

by $\left.Q_{\text {ocean }}\right)$ over the western areas of SA and SIO associated with the underlying warm SSTAs (see Fig. $3 b$ for the corresponding SST anomaly pattern), which acts as an anomalous heating of atmosphere and a damping of warm SSTAs. Over the eastern SA, the anomalous downward $Q_{\text {turb }}$ is dominated by $Q_{\text {atmos }}$, which acts to enhance the warm SSTAs therein. In December, the anomalous upward $Q_{\text {ocean }}$ over the western areas of SA and SIO remain as large as those in November. However, the anomalous downward $Q_{\text {atmos }}$ over the eastern 
SA (east of $30^{\circ} \mathrm{W}$ ) and the central SIO are higher than those in November and comparable to $Q_{\text {ocean }}$ therein. Taken together, $Q_{\text {turb }}$ in December presents a mixture of the persistent oceanic forcing and a fast feedback of the atmospheric change. Given the generally little response of $\left\langle v^{\prime} T^{\prime}\right\rangle$ in November and December (see Fig. S4 in the supplemental material), the corresponding SLP regressions (Figs. S3a,b) seem to be attributed to other processes (such as the remote upper-level divergence of mean flow) with less contribution from the divergence of eddy vorticity flux. The definite mechanism is beyond the scope of this study. In January, however, the spatial pattern of $Q_{\text {turb }}$ largely reflects the $Q_{\text {atmos }}$ change. Actually, this heat flux anomaly pattern is very similar to the simultaneous regression pattern against the $\left\langle v^{\prime} T^{\prime}\right\rangle$ time coefficients in January at lag +1 month (see Fig. 10a in the next section), indicating the influence of storm-track change on surface ocean. Overall, the anomalous upward turbulent heat fluxes linked to the warm SSTAs in the western midlatitude areas of SA and SIO presumably alter the atmospheric baroclinicity and in turn affect the synoptic eddy activities.

Next, we diagnosed the change in the dry baroclinic instability of atmosphere, which provides a baroclinic source for the development of synoptic eddies. As a measure of baroclinicity, the Eady growth rate $\sigma_{\text {Eady }}$ theoretically estimates the maximum growth rate of the most unstable synoptic mode. Figure 8 (top left) shows the lagged regression map of $\sigma_{\text {Eady }}$ averaged in December-January against the SST time coefficients in the preceding October at lag -3 month. Here the average of $\sigma_{\text {Eady }}$ in December-January is reasonable, since the $\sigma_{\text {Eady }}$ anomaly in December shows a persistence of 1 month (see Fig. 12c and discussion in section $6 a)$. It can clearly be seen that a zonal belt of positive $\sigma_{\text {Eady }}$ anomalies are located slightly to the south of $\left\langle v^{\prime} T^{\prime}\right\rangle$ anomalies (see red contours), with the maximum emerging over the western SA, which is accompanied by negative anomalies to the north. Comparing with the climatological distribution of $\sigma_{\text {Eady }}$ (Fig. 8, top right), the $\sigma_{\text {Eady }}$ anomaly pattern indicates a poleward enhancement of low-level tropospheric baroclinicity, which is found to be primarily determined by change of the meridional air temperature gradient (not shown). As such, we may expect that variation of the meridional SST gradient covaries with the $\sigma_{\text {Eady }}$ change, according to the anchoring effect of the midlatitude SST front on storm tracks (e.g., Nakamura et al. 2004).

Considering that SSTAs in the western midlatitude SA play a predominant role in affecting the SH storm tracks, we constructed the lagged composites of the meridional SST gradient and $\sigma_{\text {Eady }}$ in the western SA associated with the positive and negative phases of SST time coefficients in October at lag -3 month (see black line in Fig. 4a for reference). The years when SST time coefficients in October are greater (lower) than (minus) one standard deviation are picked out and then the meridional SST gradient in December of those years and $\sigma_{\text {Eady }}$ in December of those years, as well as in January of the following years, are averaged for the positive (negative) phase. Here we examined the meridional SST gradient in December rather than January, as the SST forcing signal in January is contaminated by the feedback of storm-track change onto ocean (see the next section). As can be seen from Fig. 9 (left), associated with the warm SSTAs in the western SA, the meridional SST gradient intensifies poleward, with an increase of $0.5 \times 10^{-3 \circ} \mathrm{C} \mathrm{km}^{-1}$, on average, to the south of $44^{\circ} \mathrm{S}$ and a decrease to the north. Correspondingly, as we expected, $\sigma_{\text {Eady }}$ in December-January shows an enhancement in the poleward flank of the climatology and a weakening in its equatorward flank. Similar results also hold for the western SIO (Fig. 9, right). Therefore, there is a generally coherent poleward intensification in the meridional SST gradient and $\sigma_{\text {Eady }}$, which is dynamically associated with the strengthening of storm-track activity therein, presumably because of the increased supply of available potential energy for the development of synoptic eddies.

To further look into the effective utilization of baroclinic energy of mean flow by synoptic eddies, we inspected the local BCEC associated with the subweekly disturbances. As can be seen from Fig. 8 (middle and bottom), the energy conversion from MAPE to EAPE significantly strengthens over the western SA and the western-central SIO, with the maximum increase over the western SIO; meanwhile, the energy conversion from EPE to EKE predominantly strengthens over the western-central SIO. The lagged regressions against the SST time coefficients at lag -2 or lag -1 month shows similar patterns as Fig. 8 (not shown). Overall, results presented above suggest that a poleward intensification of low-level tropospheric baroclinicity associated with the warm SSTAs in the western midlatitude areas of SA and SIO in the preceding late spring presumably lead to a coherent strengthening of storm-track activity in midsummer. However, although there are large negative anomalies of $\sigma_{\text {Eady }}$ emerging to the north of the SH polar-front jet, the local storm-track activity does not show the corresponding change (cf. Fig. 9, middle and bottom). Such a discrepancy may indicate a nonlinearity of storm-track response in the equatorward flank and may be mediated by the moist processes that 
Eady growth rate $850 \mathrm{mb}-\mathrm{Dec} / \mathrm{Jan}$ reg. SST-Oct

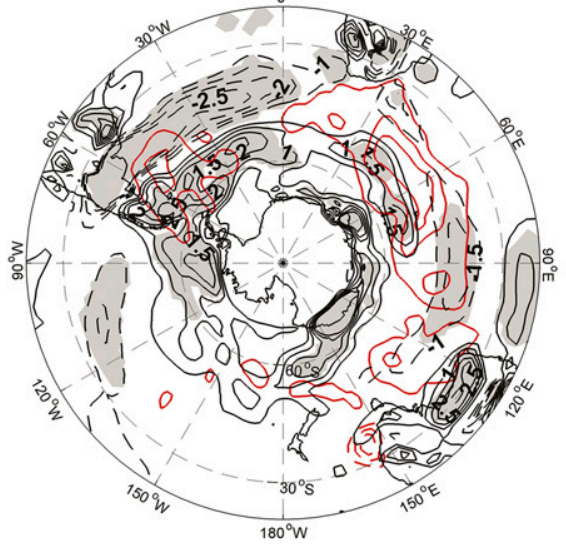

BCEC(MAPE-EAPE) $850 \mathrm{mb}-\mathrm{Dec} / \mathrm{Jan}$ reg. SST-Oct

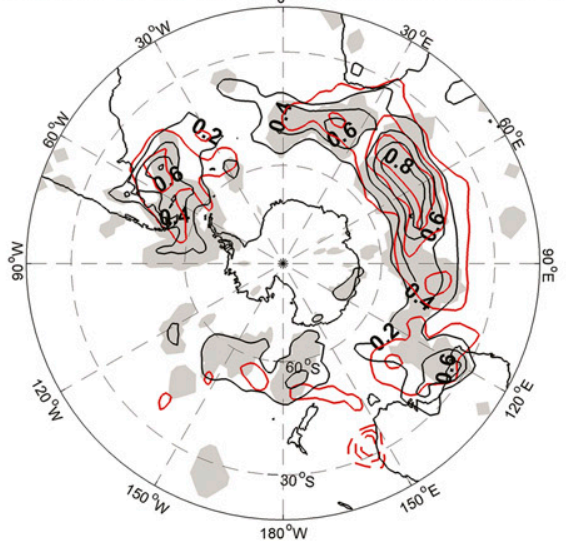

BCEC(EAPE-EKE) 850mb-Dec/Jan reg. SST-Oct

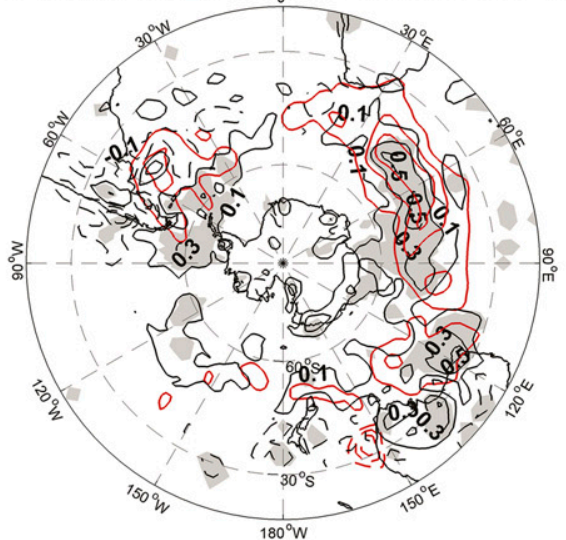

Climatology of Eady growth rate $850 \mathrm{mb}-\mathrm{Dec} / \mathrm{Jan}$

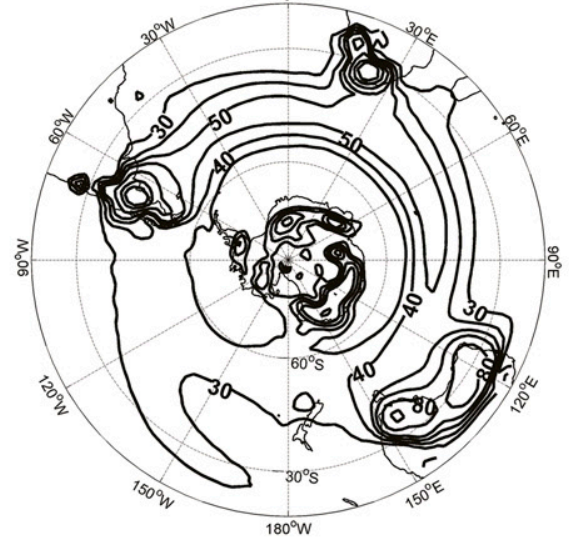

Climatology of BCEC(MAPE-EAPE) $850 \mathrm{mb}-\mathrm{Dec} / \mathrm{Jan}$

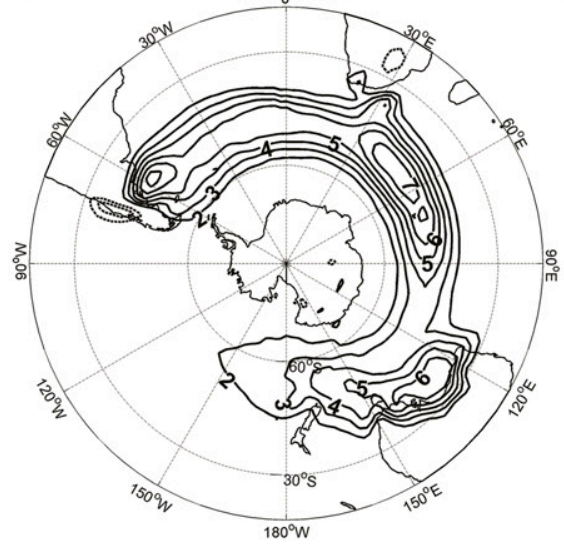

Climatology of BCEC(EAPE-EKE) $850 \mathrm{mb}-\mathrm{Dec} / \mathrm{Jan}$

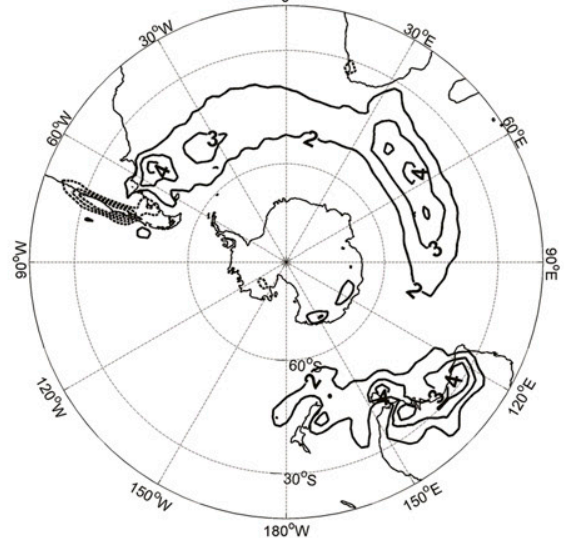

FIG. 8. (left) Lagged regression of (top) the $\sigma_{\text {Eady }}\left(10^{-2}\right.$ day $\left.^{-1}\right)$ and the BCEC $\left(\mathrm{W} \mathrm{m}^{-2}\right)$ from (middle) MAPE to EAPE and from (bottom) EAPE to EKE at $850 \mathrm{mb}$ integrated in December-January against the SST time coefficients in October at lag -3 month. Red contours signify the MCA pattern of $\left\langle v^{\prime} T^{\prime}\right\rangle$ as in Fig. 3a. (right) As in (left), but for the corresponding climatology of the $\sigma_{\text {Eady }}$ and the BCEC. Dashed contours denote negative values, and shaded areas indicate regressions significant at the $95 \%$ confidence level. 

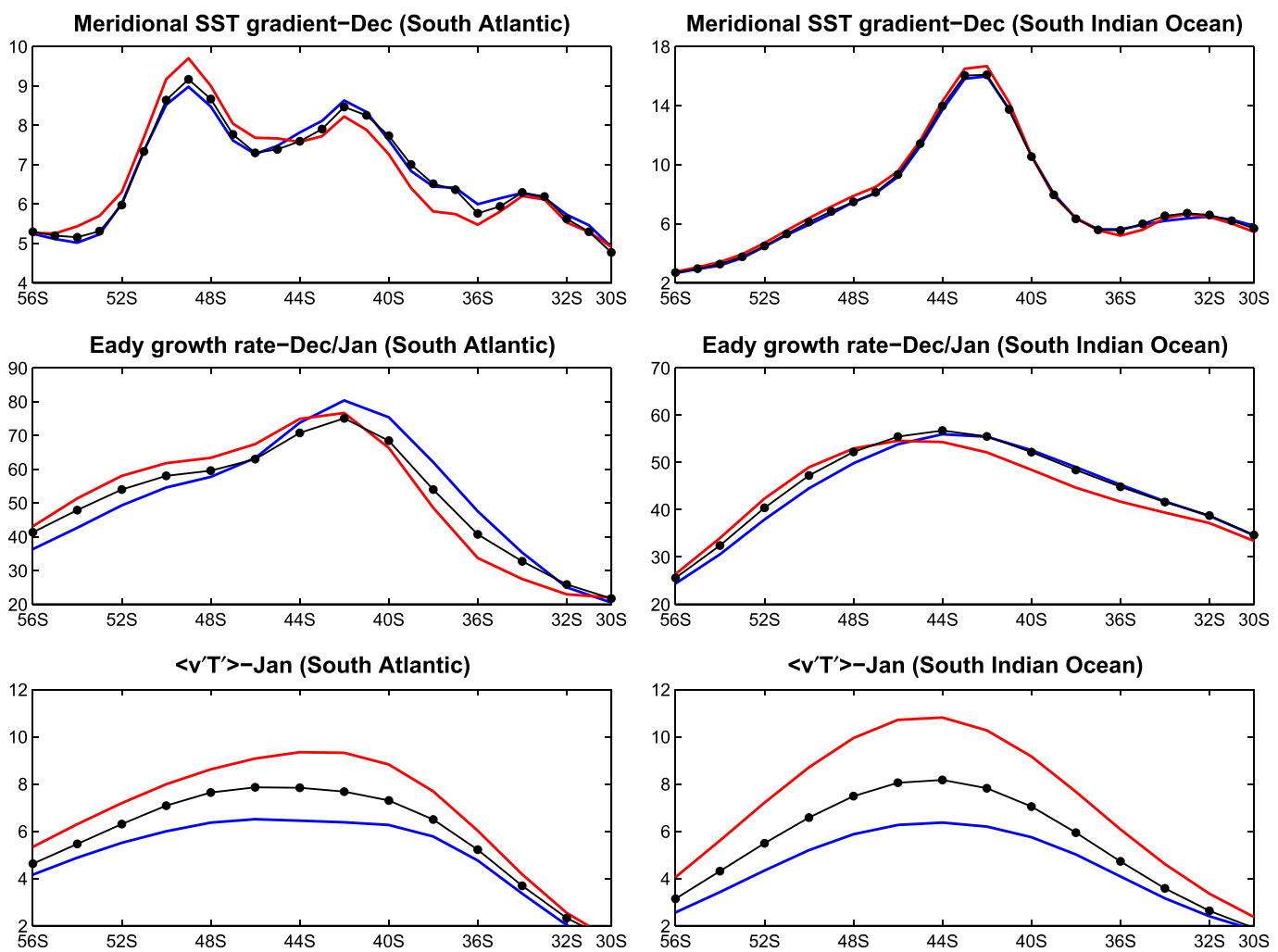

FIG. 9. Lagged composites of (top)-(bottom) the meridional SST gradient $\left(10^{-3 \circ} \mathrm{C} \mathrm{km}^{-1}\right)$ in December, $\sigma_{\text {Eady }}$ $\left(10^{-2}\right.$ day $\left.^{-1}\right)$ averaged in December-January, and $\left\langle v^{\prime} T^{\prime}\right\rangle\left(\mathrm{K} \mathrm{m} \mathrm{s}^{-1}\right)$ in January, zonally averaged over (left) the South Atlantic $\left(20^{\circ}-70^{\circ} \mathrm{W}\right)$ and (right) the south Indian Ocean $\left(30^{\circ}-75^{\circ} \mathrm{W}\right)$ for the positive phase (red line) and negative phase (blue line) of SST time coefficients in October at lag -3 month, along with the corresponding climatology (black line with dots). Note the different interval of $y$ axis for the meridional SST gradient.

are important for the amplification of individual cyclones (e.g., Kuo et al. 1991).

\section{Feedback of the storm-track change in midsummer}

The previous section shows that SST variations in October could influence the storm-track activity in the following January. On the other hand, change of the storm-track activity in midsummer continues to drive SST variations, given that the SC peaks at lag +1 month when both $\left\langle v^{\prime} T^{\prime}\right\rangle$ and $\left\langle v^{\prime} v^{\prime}\right\rangle$ in January lead SST (recall Fig. 2). The $\left\langle v^{\prime} T^{\prime}\right\rangle$ forcing pattern in January (Fig. 3e) strongly resembles the $\left\langle v^{\prime} T^{\prime}\right\rangle$ anomaly pattern in response to SSTAs in the preceding October-December (Figs. 3a-c). Such strengthening of $\left\langle v^{\prime} T^{\prime}\right\rangle$ in January is found to induce the dipolelike patterns of SSTAs in the subtropical SA, subtropical SIO, and midlatitude SP, respectively. Specifically, for the SA, a meridionaldipolelike structure exhibits warm and cold SSTAs in the southern and northern subtropics, respectively; for the SIO, a zonal-dipolelike structure along $30^{\circ} \mathrm{S}$ exhibits warm and cold SSTAs in the western and eastern parts, respectively; for the midlatitude SP, a meridionaldipolelike structure exhibits warm SSTAs along $30^{\circ}-$ $40^{\circ} \mathrm{S}$ with the maximum off the southeastern coast of Australia and cold SSTAs in the subpolar region. Likewise, the intensified $\left\langle v^{\prime} v^{\prime}\right\rangle$ in January also has association with the SST dipolelike patterns in the southern oceans (Fig. 5c), which strongly resembles Fig. 3e. The simultaneous MCA pattern of SST in January (Fig. 3d) bears great similarities to that obtained at lag +1 month, but largely differs from the SST forcing pattern in the preceding late spring (at lag -3 month). This indicates that the instantaneous MCA result primarily reflects the storm-track forcing on SST.

To further qualitatively assess the physical processes responsible for the SSTAs induced by anomalous $\left\langle v^{\prime} T^{\prime}\right\rangle$ in January, following GW15, we analyzed three heat budget terms that are directly associated with the atmospheric forcing: the net surface heat flux $Q_{\text {net }}$, the horizontal heat advection by Ekman current $-\left(\rho C_{p}\right.$ $\left.h \mathbf{V}_{\mathrm{Ek}} \cdot \nabla_{h} T\right)$, and the vertical heat advection by Ekman pumping $-\left[\rho C_{p} h w_{\mathrm{ep}}(\partial T / \partial z)\right]$. The horizontal heat 
(a) Net surface heat flux-Jan reg. $v^{\prime} T^{\prime}-J a n$

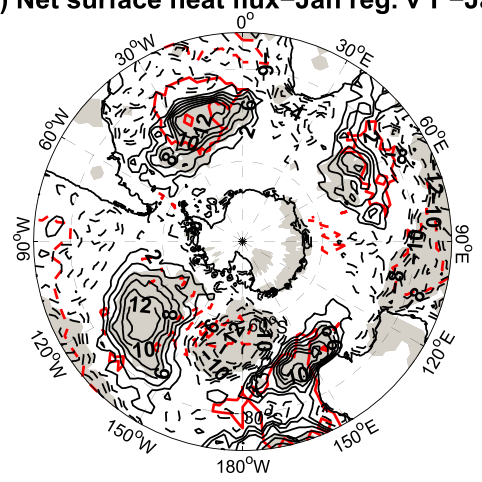

(b) Ekman advection-Jan reg. $v^{\top} T^{\prime}-J a n$

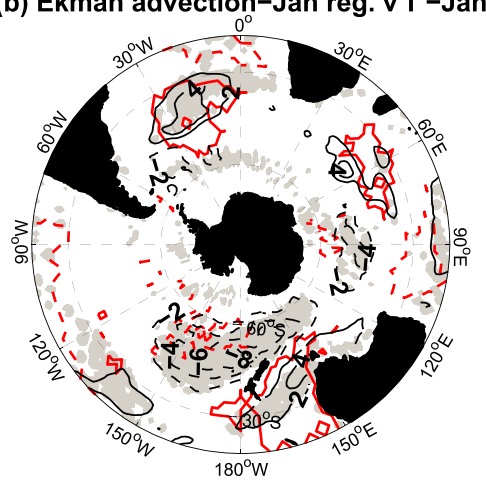

(c) Vertical advection-Jan reg. $\mathrm{VT}^{\prime}-\mathrm{Jan}$

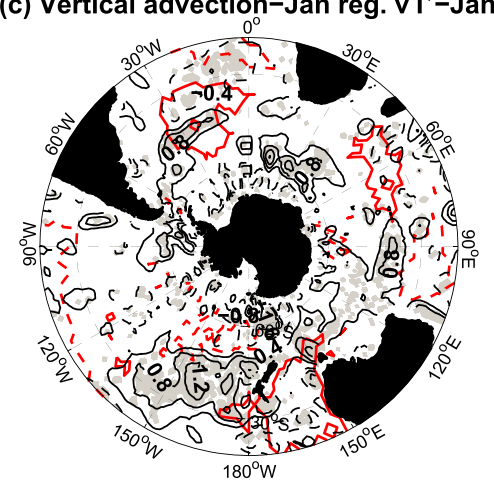

FIG. 10. Simultaneous regression of (a) the $Q_{\text {net }}$ (positive downward), (b) the horizontal heat advection by Ekman currents, and (c) the vertical heat advection by Ekman pumping against the $\left\langle v^{\prime} T^{\prime}\right\rangle$ time coefficients in January at lag $+1 \mathrm{month}$. The contour interval is $2 \mathrm{~W} \mathrm{~m}{ }^{-2}$ for (a),(b) and $0.4 \mathrm{~W} \mathrm{~m}^{-2}$ for (c). Red contours signify the MCA pattern of SST as in Fig. 3e. Dashed contours denote negative values, and shaded areas indicate regression values significant at the $95 \%$ confidence level.

advection by geostrophic current related to the stormtrack variation is found to be generally insignificant, thus, this term is ignored here. Here $\rho C_{p}$ is the volumetric heat capacity of sea seawater, $T$ is the ocean temperature, $h$ is the mixed layer depth, $\mathbf{V}_{\mathrm{Ek}}$ is the horizontal Ekman velocity, and $w_{\mathrm{ep}}$ is the Ekman pumping velocity [i.e., $w_{\text {ep }}=\operatorname{curl}(\tau / \rho f)$, where $\tau$ is the horizontal wind stress vector and the other notation is standard].

Figure 10 shows the simultaneous regressions of the above three terms against the $\left\langle\boldsymbol{v}^{\prime} T^{\prime}\right\rangle$ time coefficients in January taken from the MCA mode at lag +1 month. It is found that the spatial pattern of SSTAs in response to $\left\langle\boldsymbol{v}^{\prime} T^{\prime}\right\rangle$ anomalies (Fig. 3e) is, to the first order, determined by changes of the net surface heat flux, given the resemblance between $Q_{\text {net }}$ (Fig. 10a) and SST responses in space. The Ekman advections (Fig. 10b), however, contribute to regional SSTAs. Specifically, warm SSTAs in the southern subtropical SA are partly generated by the Ekman warm advection; warm SSTAs off the southeastern coast of Australia and cold SSTAs the western subpolar SP are partly attributed to the Ekman warm and cold advections, respectively. The Ekman-pumping-induced vertical advections (Fig. 10c) marginally contribute to warm SSTAs in the centralwestern subtropical SP, albeit with the magnitude smaller by one order than the other two terms.

Further inspection has found that the total Ekman advection $\mathbf{V}_{\mathrm{Ek}} \cdot \nabla T$ is dominated by the advection of mean SST by the anomalous Ekman current $\mathbf{V}_{\mathrm{Ek}}^{\prime} \cdot \nabla \bar{T}$ (not shown), which indicates a direct forcing of the $\left\langle v^{\prime} T^{\prime}\right\rangle$-induced change of the surface westerly on ocean. Given that, we composited anomalies of the surface zonal wind and the divergence of the horizontal Eliassen-Palm flux $\nabla \cdot \mathbf{E}$ that indicates the eddy-induced acceleration of the westerly, associated with the intensification of $\left\langle v^{\prime} T^{\prime}\right\rangle$. Following Trenberth (1986), the horizontal Eliassen-Palm flux is defined as $\mathbf{E}=\left(\left\langle\boldsymbol{v}^{\prime 2}-\right.\right.$ $\left.\left.u^{\prime 2}\right\rangle / 2,\left\langle-u^{\prime} v^{\prime}\right\rangle\right)$, where $u^{\prime}$ and $v^{\prime}$ denote the 2-8-day bandpass-filtered zonal and meridional winds, respectively, and the angle brackets represent the monthly time average. As shown in Fig. 11a, the surface zonal wind anomalies display a meridional dipole pattern. It indicates an enhanced (reduced) westerly in the poleward (equatorward) flank of the polar-front jet over the SA and SIO and an acceleration of the polar-front jet over the SP. Such features are generally consistent with the $\nabla \cdot \mathbf{E}$ change (Fig. 11b), which broadly shows an increase of divergence slightly to the south of the SH polar-front jet and the anomalous convergence over the southern subtropics of SA and SIO, regardless of the untidy manifestation of change and climatology of $\nabla \cdot \mathbf{E}$. Since $\left\langle v^{\prime} T^{\prime}\right\rangle$ plays an important role in transporting the mean-flow westerly momentum downward to maintain a low-level westerly jet, it is expected that the $\left\langle v^{\prime} T^{\prime}\right\rangle$ induced change of westerly has an equivalent barotropic structure. Indeed, the upper-level zonal wind displays an anomaly pattern very similar to that at surface (cf. Figs. 11c and 11a), which is dynamically consistent with the upper-level $\nabla \cdot \mathbf{E}$ change that shows a well-defined increase of divergence along its climatology (Fig. 11d). Therefore, the coherent changes of zonal wind and $\nabla \cdot \mathbf{E}$ with an equivalent barotropic structure demonstrate the feedback forcing of anomalous storm-track activity onto the mean flow, which in turn partly drives the anomalous Ekman current and turbulent heat flux. It is worthwhile to mention that the SAM variability also contributes to the surface zonal wind change, since there is a significant correlation (0.40) between the $\left\langle v^{\prime} T^{\prime}\right\rangle$ time coefficients and the SAM index in January (Fig. 4b). 
(a) Surface, wind-Jan

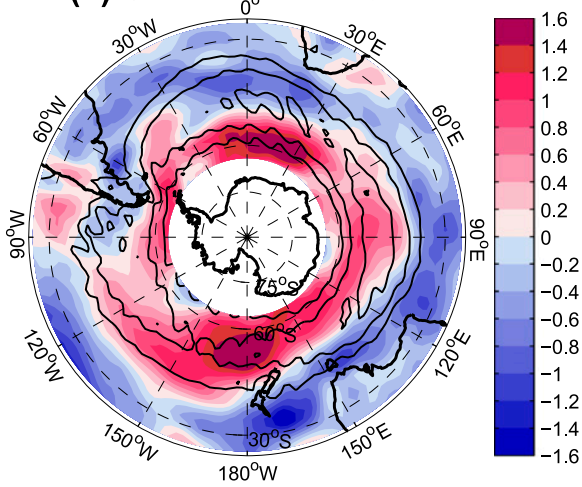

(c) U300-Jan

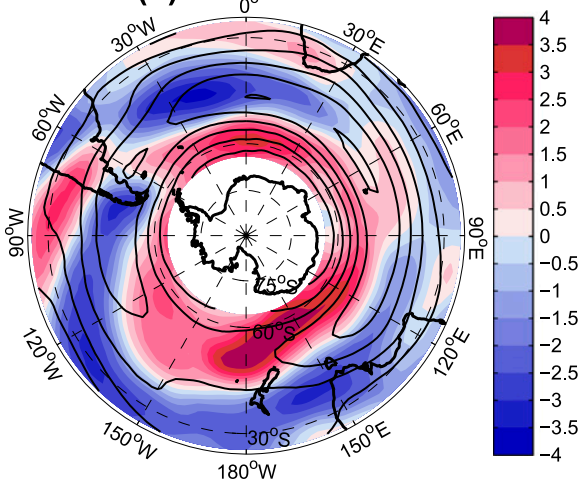

(b) Divergence of E-P flux $850 \mathrm{mb}-J a n$

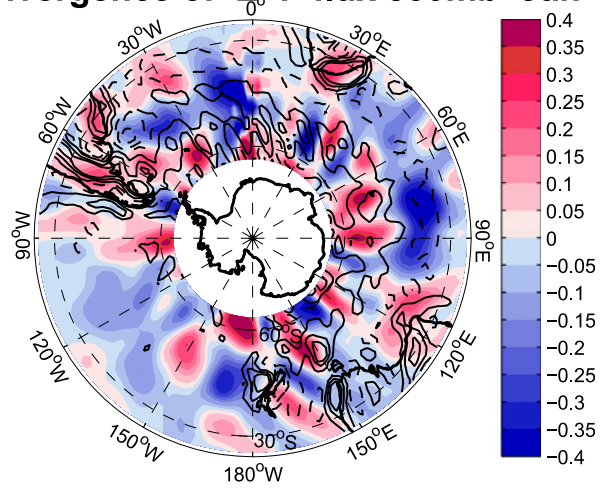

(d) Divergence of E-P flux $300 \mathrm{mb}-J a n$

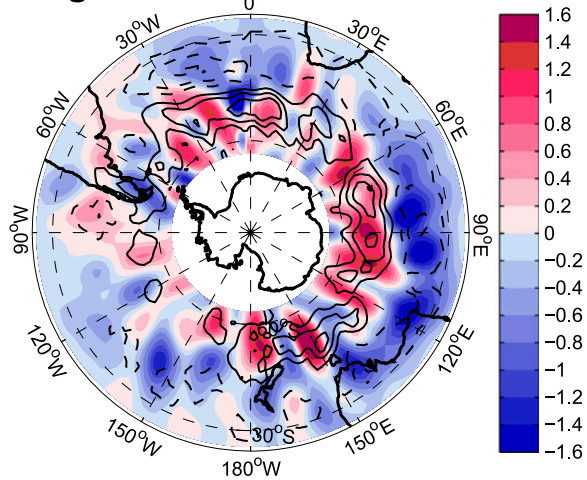

FIG. 11. Composited anomalies (color shading) of (a) surface zonal wind $\left(\mathrm{m} \mathrm{s}^{-1}\right)$, (b) $850-\mathrm{mb} \nabla \cdot \mathbf{E}\left(10^{-2} \mathrm{~m}^{2} \mathrm{~s}^{-2} \mathrm{~km}^{-1}\right)$, (c) 300-mb zonal wind $\left(\mathrm{m} \mathrm{s}^{-1}\right)$, and (d) $300-\mathrm{mb} \nabla \cdot \mathbf{E}\left(10^{-2} \mathrm{~m}^{2} \mathrm{~s}^{-2} \mathrm{~km}^{-1}\right)$ for the positive phase of the $\left\langle v^{\prime} T^{\prime}\right\rangle$ time coefficients in January at lag +1 month, along with the corresponding climatology (black contours and dashed for negative values). The contour interval is $3 \mathrm{~m} \mathrm{~s}^{-1}$ for (a), $0.4 \times 10^{-2} \mathrm{~m}^{2} \mathrm{~s}^{-2} \mathrm{~km}^{-1}$ for (b), $6 \mathrm{~m} \mathrm{~s}^{-1}$ for (c), and $1 \times 10^{-2} \mathrm{~m}^{2} \mathrm{~s}^{-2} \mathrm{~km}^{-1}$ for $(\mathrm{d})$. The composite for the positive phase is based on the years when the $\left\langle v^{\prime} T^{\prime}\right\rangle$ time coefficients (see gray line in Fig. $4 \mathrm{~b}$ for reference) are greater than one standard deviation.

\section{Discussion}

\section{a. An important role of SST in the western midlatitude South Atlantic}

As for the oceanic influence on storm tracks, SSTAs in the western midlatitude SA in October are suggested to play a predominant role in affecting the SH storm tracks in the following January. It should be noted that the detected 3-month lag for the storm-track response primarily reflects the persistence of SSTAs rather than the occurrence of the SST forcing in advance, as pointed out by Czaja and Frankignoul (2002). We further examined autocorrelations of SST, $\sigma_{\text {Eady }}$, and $\left\langle v^{\prime} T^{\prime}\right\rangle$ anomalies over the western SA from October to March. For $\left\langle v^{\prime} T^{\prime}\right\rangle$, the autocorrelation between two neighboring months is much lower and insignificant, indicating that stormtrack anomalies are barely persistent (Fig. 12a). However, the SSTAs in late spring clearly exhibit large persistence of 3 months at least (Fig. 12b), which could explain why the influence of SSTAs on storm tracks that is likely to happen in January can be detected by using
SSTAs in October. Indeed, warm SSTAs in the western midlatitude SA in the preceding October persist into January (see Fig. 13), which is expected to enhance the meridional air temperature gradient and thus strengthen the local storm tracks. It is also interesting to see that the $\sigma_{\text {Eady }}$ anomalies in November-December are able to persist into December-January (Fig. 12c). Such persistence of atmospheric baroclinicity, combined with the persistent SSTAs from October to January, could help to energize the anomalous eddy activities in January. Similar autocorrelations are obtained for other regions.

Warm SSTAs in the western midlatitude SA, however, not only induce the local storm-track response, but also exert far-reaching influence on storm tracks over the SIO (recall Fig. 6a). This could be attributed to an atmospheric process called "downstream development," which enables synoptic eddies to be developed farther in the downstream away from source region (Chang et al. 2002). Alternatively, we speculate that SSTAs in the western midlatitude SA trigger a positive ocean-atmosphere feedback in the western-central 
(a) Autocorrelation of $\left\langle v^{\prime} T^{\prime}\right\rangle$ anomalies

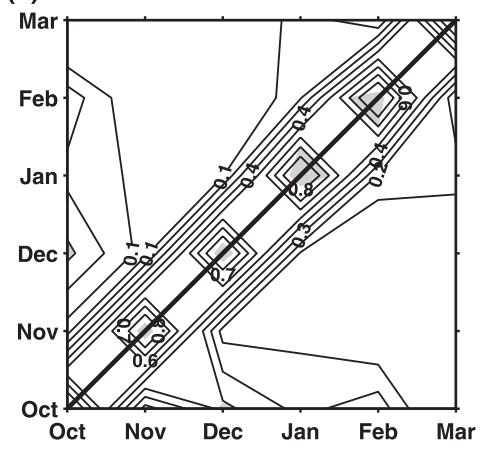

(b) Autocorrelation of SSTAs

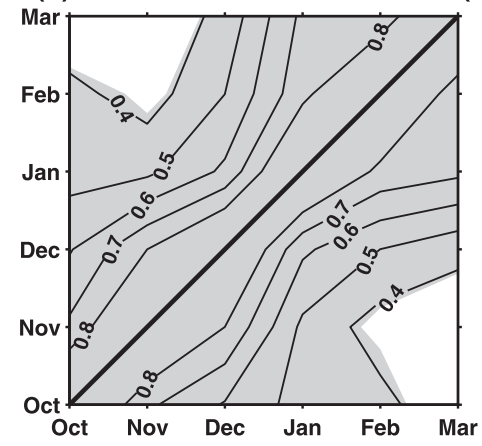

(c) Autocorrelation of Eady growth rate anomalies

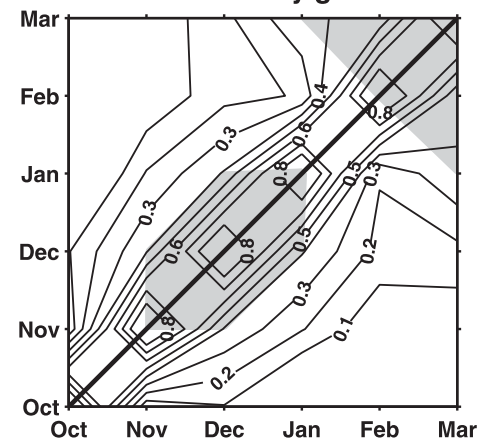

FIG. 12. Autocorrelation coefficients of (a) $\left\langle v^{\prime} T^{\prime}\right\rangle$, (b) SST, and (c) $\sigma_{\text {Eady }}$ and time series plotted as a function of the calendar months from October to March, with the thick line denoting the simultaneous correlations (i.e., 1.0). The $\left\langle v^{\prime} T^{\prime}\right\rangle$, SST, and $\sigma_{\text {Eady }}$ time series are derived from the area-averaged anomalies in the western SA (box in Fig. 3a). Shading and dashed lines indicate the $95 \%$ confidence level.

SIO, which is helpful to sustain SSTAs and in turn facilitate a strengthening of storm-track activity over the SIO. Indeed, as shown in Fig. 13, warm SSTAs in the western-central SIO, which are associated with the SST variations in the western midlatitude SA in October, display a gradual increase in the following November-January. Overall, whether the SST variations in the western midlatitude SA in October influence the $\mathrm{SH}$ storm tracks in the following January through either the atmospheric dynamical process or the ocean-atmosphere coupling or both ways need to be addressed in a future study. Particularly, sensitivity experiments conducted by a fully coupled climate model and its stand-alone atmospheric component, respectively, are needed.

Further inspection also suggests that the identified influence of SST variations, particularly in the western midlatitude SA, in the preceding October on the SH storm tracks in January is active and significant at interannual time scales. Figure 14 shows the results of multitaper spectrum analysis (Mann and Lees 1996). The power spectrum of SST time coefficients in October at lag -3 month exhibits two spectral peaks at 4 and $8 \mathrm{yr}$, albeit with the confidence level only reaching $80 \%$ (Fig. 14a). However, the $\left\langle v^{\prime} T^{\prime}\right\rangle$ time coefficients in January at lag -3 month displays a spectral peak at $4 \mathrm{yr}$ (significant at the $90 \%$ confidence level), but with a suppression of peak at $8 \mathrm{yr}$ (Fig. 14b). Note that much of the ENSO influence has been subtracted beforehand, which thus excludes ENSO as a remote forcing tool for the interannual variability of both SST and storm tracks identified here. More importantly, the time series of SSTAs area-averaged in the western SA in the preceding October also shows a unique spectral peak at $4 \mathrm{yr}$ (marginally significant at the $95 \%$ confidence level; Fig. 14c), which further supports the abovementioned suggestion regarding the predominant role of the western SA SSTAs in late spring in affecting the SH storm tracks in midsummer. This significant peak also can be found in the power spectrum of the January SAM index (Fig. 14d), although there is no significant relationship between the MCA time coefficients and the January SAM index, as mentioned before. In the past, SAM had long been considered as an atmospheric internal variability uncoupled to SST. However, the fact that a significant spectral peak at $4 \mathrm{yr}$ simultaneously appears in both SSTAs and SAM (Fig. 14) may suggest that SST variations could feed back to the SAM in midsummer. Ogawa et al. (2016) have revealed the influence of the midlatitude SST front on the wintertime signature of SAM and the dynamical association of SAM with the underlying SST conditions in the summertime is worth being addressed in the future.

\section{b. Timing of the discernible response of storm tracks}

Last but not least, an open question arises as to why the storm-track response to the midlatitude SST variation in the southern oceans is particularly discernible in midsummer. To shed a bit more light on this issue, we have conducted two sensitivity experiments with the Community Atmosphere Model, version 5.3 (CAM5.3), which reasonably simulates the climatological spatial distribution of $\left\langle v^{\prime} T^{\prime}\right\rangle$ albeit with a bias toward higher amplitude through the year (Fig. S5 in the supplemental material). One experiment is that the SSTAs as shown in Fig. 3a, being multiplied by a factor of 5, are added to the climatological mean SST in November as the prescribed forcing. The other one is that the same SSTAs are added to the climatological mean SST in January as the prescribed forcing. The atmosphere during other months is forced by the monthly climatological-mean SST. More details are referred to in the supplemental material. As shown in Fig. S6, the spatial distribution of the simulated $\left\langle v^{\prime} T^{\prime}\right\rangle$ response in January resembles the corresponding 
(a) SST-Oct

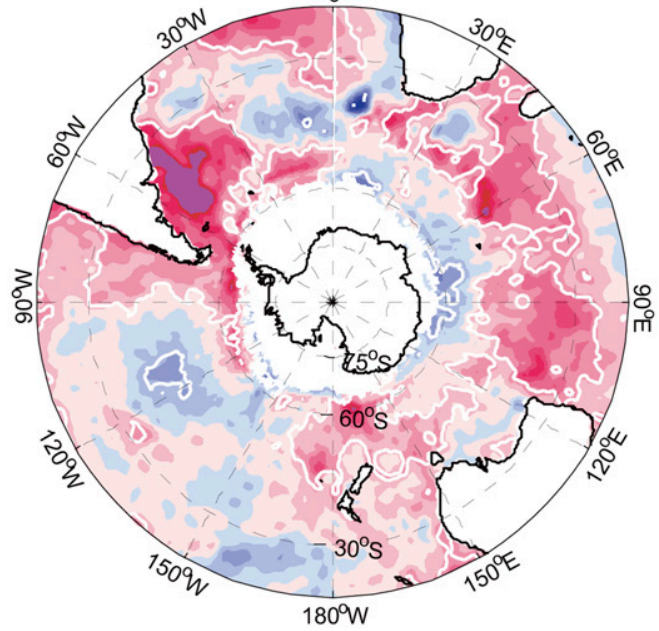

(c) $\mathrm{SST}_{0}-\mathrm{Dec}$

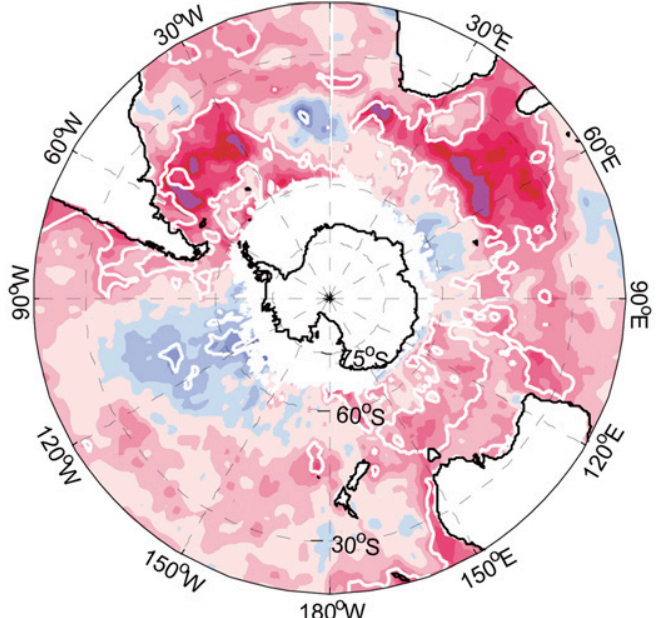

(b) $\mathrm{SST}_{0}-\mathrm{Nov}$

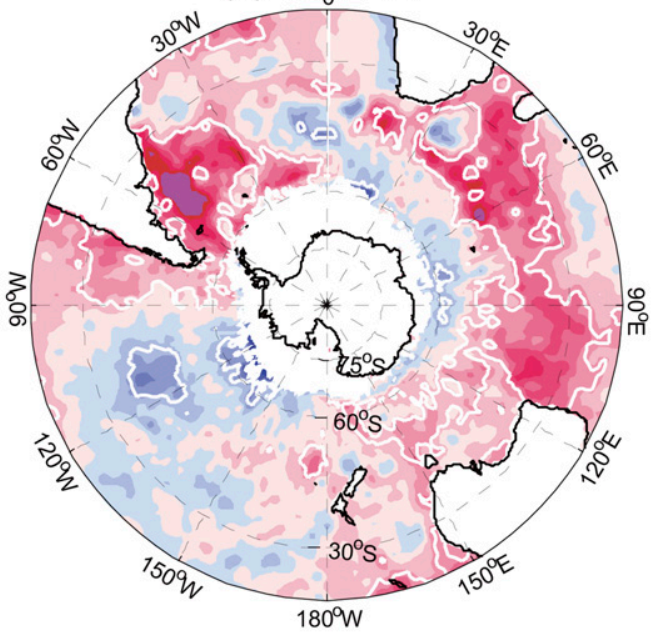

(d) $\mathrm{SST}_{0} \mathrm{t}-\mathrm{Jan}$

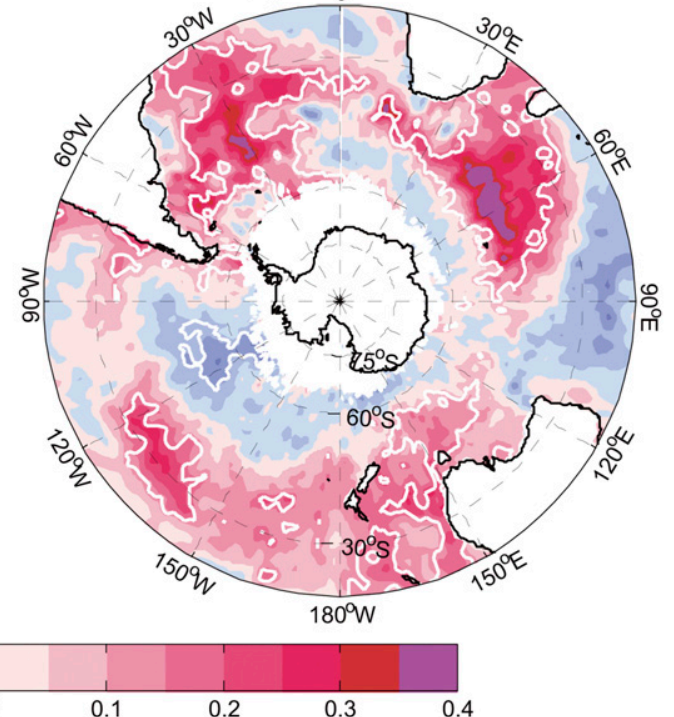

FIG. 13. Regression of SSTAs $\left({ }^{\circ} \mathrm{C}\right)$ in (a)-(d) October-January against the SST time series in October derived from the area-averaged SSTAs in the western SA (box in Fig. 3a). White contours indicate regression values significant at the $95 \%$ confidence level.

MCA pattern shown in Fig. 3a, although its amplitude is only about 1-2 times the latter under the fivefold SSTA forcing. However, the simulated $\left\langle v^{\prime} T^{\prime}\right\rangle$ response in November exhibits a totally different pattern. Since the difference between these two experiments lies in the atmospheric background, the results suggest that the discernible influence of SST variations on storm tracks is indeed sensitive to the differences in the atmospheric mean state. Early studies also have reported the subseasonal sensitivity of the atmospheric response to the extratropical SSTAs in the Northern Hemisphere (Peng et al. 1997; Taguchi et al. 2012). However, physical mechanisms involved remain uncertain. According to Nakamura and Shimpo (2004), it is speculated that the relatively weaker subtropical jet stream in summer than in winter may set up a background for the transient eddies, which could convert more efficiently the anomalous mean-flow baroclinic energy induced by the oceanic-front variation for their growth. In addition, the warm SSTAs in summer may provide more moisture through the increase of latent heat release to the warm sector of individual storms and in turn facilitate the storm development, implied from the finding of Booth et al. (2012). 


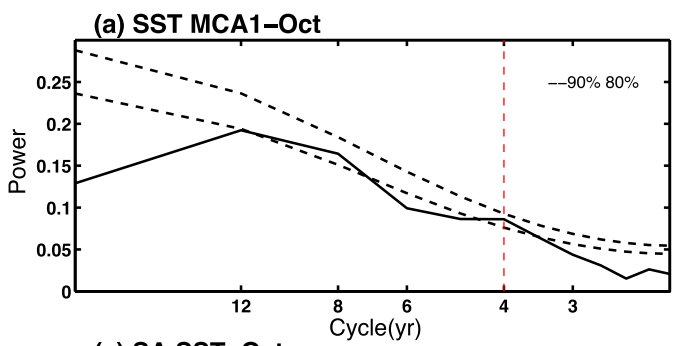

(c) SA SST-Oct

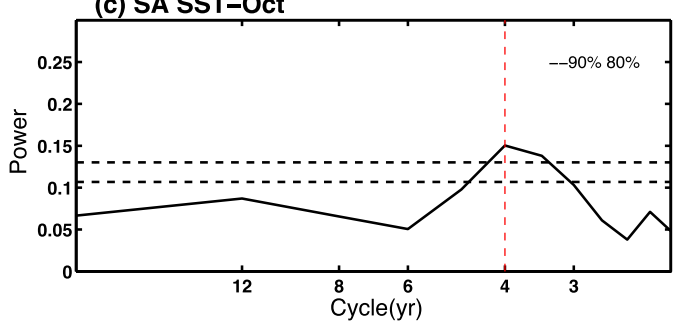

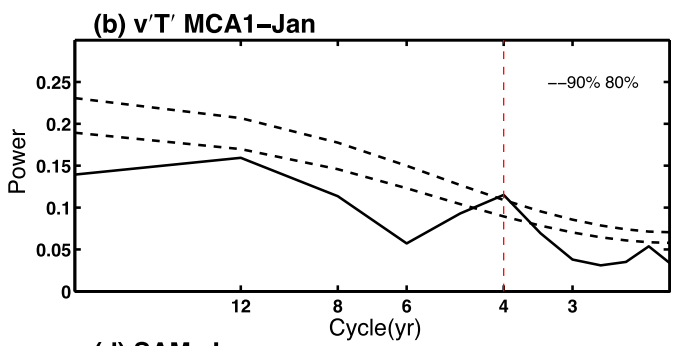

(d) SAM-Jan

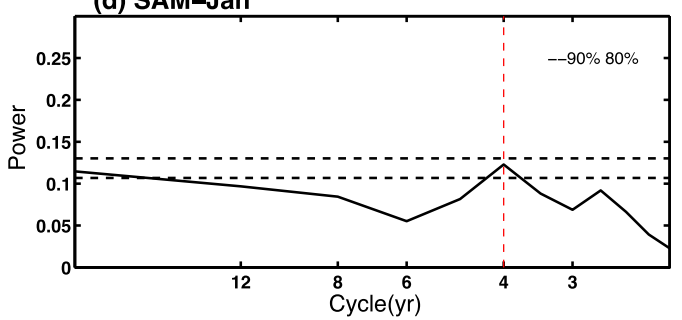

FIG. 14. Power spectrum of (a) SST and (b) $\left\langle v^{\prime} T^{\prime}\right\rangle$ time coefficients in October and January, respectively, derived from the first MCA mode at lag -3 month. (c) As in (a), but for the time series of SSTAs area averaged in the western SA (box in Fig. 3a). (d) The power spectrum of the SAM index in January (red dashed line in Fig. 4a). Dashed lines indicate the $80 \%$ and $90 \%$ confidence levels.

\section{Conclusions}

The seasonal coupling between the midlatitude SST variations in the southern oceans and changes of stormtrack activities in the lower and upper troposphere throughout the year is investigated based on the lagged MCA. We have shown that the coupling is characterized by a pronounced seasonal dependence, with the coupling in midsummer being the most prominent. On one hand, SST variations in late spring (primarily October) are likely to influence the storm-track activities in the following midsummer (January). That is, warm SSTAs in the western areas of SA and SIO at midlatitudes could result in a systematic strengthening of both the low-level and upper-level eddy activities, which are represented by the poleward transient eddy heat flux at $850 \mathrm{mb}$ (i.e., $\left.\left\langle v^{\prime} T^{\prime}\right\rangle\right)$ and the synoptic-scale meridional wind velocity variance at $250 \mathrm{mb}$ (i.e., $\left\langle\boldsymbol{v}^{\prime} \boldsymbol{v}^{\prime}\right\rangle$ ), respectively. The coherent intensification of the meridional SST gradient and the lower-tropospheric baroclinicity associated with such midlatitude warm SSTAs in the preceding late spring is presumed to be responsible for the strengthening of eddy activities in midsummer. Particularly, our results suggest that interannual variability (with a spectral peak at $4 \mathrm{yr}$ ) of SSTAs in the western midlatitude SA (west of $30^{\circ} \mathrm{W}$ ) in October could play a predominant role in driving the corresponding variability of the entire $\mathrm{SH}$ storm tracks in the following January.

On the other hand, the strengthened storm-track activities in January continue to induce the dipolelike patterns of SSTAs in the midlatitude southern oceans. Specifically, the SA shows warm and cold SSTAs in the southern and northern subtropics, respectively; the SIO shows warm and cold SSTAs in the western and eastern parts along $30^{\circ} \mathrm{S}$, respectively; and the SP exhibits warm SSTAs along $30^{\circ}-40^{\circ} \mathrm{S}$ with the maximum off the southeastern coast of Australia and cold SSTAs in the subpolar region. Such SST response patterns are, to the first order, determined by changes of the net surface heat flux. Additional contributions to SSTAs in the southern subtropical SA and the western midlatitude SP come from the advections of mean SST by the anomalous Ekman currents, which are in part associated with the anomalous surface westerlies driven by the stormtrack changes.

Acknowledgments. We appreciate four anonymous reviewers for their comments that helped to improve the manuscript substantially. This work is supported by National Natural Science Foundation of China (NSFC) Projects (41506009, 41490643, 41490640, 41521091, and U1606402) and Zhejiang Provincial Natural Science Foundation of China (LQ14D050001).

\section{REFERENCES}

Blackmon, M. L., J. M. Wallace, N. C. Lau, and S. L. Mullen, 1977: An observational study of the Northern Hemisphere wintertime circulation. J. Atmos. Sci., 34, 1040-1053, https://doi.org/ 10.1175/1520-0469(1977)034<1040:AOSOTN>2.0.CO;2.

Booth, J. F., L. Thompson, J. Patoux, and K. A. Kelly, 2012: Sensitivity of midlatitude storm intensification to perturbations in the sea surface temperature near the Gulf Stream. Mon. Wea. Rev., 140, 1241-1256, https://doi.org/10.1175/ MWR-D-11-00195.1. 
Bretherton, C. S., M. Widmann, V. P. Dymnikov, J. M. Wallace, and I. Bladé, 1999: The effective number of spatial degrees of freedom of a time-varying field. J. Climate, 12, 1990-2009, https:// doi.org/10.1175/1520-0442(1999)012<1990:TENOSD>2.0.CO;2.

Cai, M., S. Yang, H. M. Van den Dool, and V. E. Kousky, 2007: Dynamical implications of the orientation of atmospheric eddies: A local energetics perspective. Tellus, 59A, 127-140, https://doi.org/10.1111/j.1600-0870.2006.00213.x.

Carton, J. A., and B. S. Giese, 2008: A reanalysis of ocean climate using Simple Ocean Data Assimilation (SODA). Mon. Wea. Rev., 136, 2999-3017, https://doi.org/10.1175/ 2007MWR1978.1.

Cayan, D. R., 1992: Latent and sensible heat flux anomalies over the northern oceans: Driving the sea surface temperature. J. Phys. Oceanogr., 22, 859-881, https://doi.org/10.1175/ 1520-0485(1992)022<0859:LASHFA > 2.0.CO;2.

Chang, E. K. M., S. Lee, and K. L. Swanson, 2002: Storm track dynamics. J. Climate, 15, 2163-2183, https://doi.org/10.1175/15200442(2002)015<02163:STD > 2.0.CO;2.

Compo, G. P., and Coauthors, 2011: The Twentieth Century Reanalysis Project. Quart. J. Roy. Meteor. Soc., 137, 1-28, https:// doi.org/10.1002/qj.776.

Czaja, A., and C. Frankignoul, 2002: Observed impact of Atlantic SST anomalies on the North Atlantic Oscillation. J. Climate, 15, 606-623, https://doi.org/10.1175/1520-0442(2002)015<0606: OIOASA $>2.0 . \mathrm{CO} ; 2$.

Field, P. R., and R. Wood, 2007: Precipitation and cloud structure in midlatitude cyclones. J. Climate, 20, 233-254, https:// doi.org/10.1175/JCLI3998.1.

Gan, B., and L. Wu, 2013: Seasonal and long-term coupling between wintertime storm tracks and sea surface temperature in the North Pacific. J. Climate, 26, 6123-6136, https://doi.org/ 10.1175/JCLI-D-12-00724.1.

$\longrightarrow$, and $\longrightarrow$, 2015: Feedbacks of sea surface temperature to wintertime storm tracks in the North Atlantic. J. Climate, 28, 306-323, https://doi.org/10.1175/JCLI-D-13-00719.1.

Gastineau, G., and C. Frankignoul, 2012: Cold-season atmospheric response to the natural variability of the Atlantic meridional overturning circulation. Climate Dyn., 39, 37-57, https://doi.org/10.1007/s00382-011-1109-y.

Guo, Y., E. K. M. Chang, and S. S. Leroy, 2009: How strong are the Southern Hemisphere storm tracks? Geophys. Res. Lett., 36, L22806, https://doi.org/10.1029/2009GL040733.

Hotta, D., and H. Nakamura, 2011: On the significance of sensible heat supply from the ocean in the maintenance of mean baroclinicity along storm tracks. J. Climate, 24, 3377-3401, https:// doi.org/10.1175/2010JCLI3910.1.

Joyce, T. M., Y.-O. Kwon, and L. Yu, 2009: On the relationship between synoptic wintertime atmospheric variability and path shifts in the Gulf Stream and Kuroshio Extension. J. Climate, 22, 3177-3192, https://doi.org/10.1175/2008JCLI2690.1.

Kalnay, E., and Coauthors, 1996: The NCEP/NCAR 40-Year Reanalysis Project. Bull. Amer. Meteor. Soc., 77, 437-471, https:// doi.org/10.1175/1520-0477(1996)077<0437:TNYRP>2.0.CO;2.

Kug, J. S., F. F. Jin, J. H. Par, H. L. Ren, and I. S. Kang, 2010: A general rule for synoptic-eddy feedback onto low-frequency flow. Climate Dyn., 35, 1011-1026, https://doi.org/10.1007/ s00382-009-0606-8.

Kuo, Y.-H., R. J. Reed, and S. Low-Nam, 1991: Effects of surface energy fluxes during the early development and rapid intensification stages of seven explosive cyclones in the western Atlantic. Mon. Wea. Rev., 119, 457-476, https://doi.org/ 10.1175/1520-0493(1991)119<0457:EOSEFD>2.0.CO;2.
Kushnir, Y., W. A. Robinson, I. Bladé, N. M. J. Hall, S. Peng, and R. Sutton, 2002: Atmospheric GCM response to extratropical SST anomalies: Synthesis and evaluation. J. Climate, 15, 2233-2256, https://doi.org/10.1175/1520-0442(2002)015<2233: AGRTES $>2.0 . \mathrm{CO} ; 2$.

Kwon, Y. O., and T. M. Joyce, 2013: Northern Hemisphere winter atmospheric transient eddy heat fluxes and the Gulf Stream and Kuroshio-Oyashio Extension variability. J. Climate, 26, 9839-9859, https://doi.org/10.1175/JCLI-D-12-00647.1.

Lau, N. C., 1988: Variability of the observed midlatitude storm tracks in relation to low-frequency changes in the circulation pattern. J. Atmos. Sci., 45, 2718-2743, https://doi.org/10.1175/ 1520-0469(1988)045<2718:VOTOMS >2.0.CO;2.

Lindzen, R. S., and B. F. Farrell, 1980: A simple approximation result for the maximum growth rate of baroclinic instabilities. J. Atmos. Sci., 37, 1648-1654, https://doi.org/10.1175/15200469(1980)037<1648:ASARFT>2.0.CO;2.

Lorenz, D. J., and D. L. Hartmann, 2003: Eddy-zonal flow feedback in the Northern Hemisphere winter. J. Climate, 16, 1212-1227, https://doi.org/10.1175/1520-0442(2003)16<1212: EFFITN $>2.0 . \mathrm{CO} ; 2$.

Mann, M. E., and J. M. Lees, 1996: Robust estimation of background noise and signal detection in climatic time series. Climatic Change, 33, 409-445, https://doi.org/10.1007/ BF00142586.

Nakamura, H., and A. Shimpo, 2004: Seasonal variations in the Southern Hemisphere storm tracks and jet streams as revealed in a reanalysis dataset. J. Climate, 17, 1828-1844, https://doi.org/ 10.1175/1520-0442(2004)017<1828:SVITSH>2.0.CO;2.

, T. Sampe, Y. Tanimoto, and A. Shimpo, 2004: Observed associations among storm tracks, jet streams and midlatitude oceanic fronts. Earth's Climate: The Ocean-Atmosphere Interaction, Geophys. Monogr., Vol. 147, Amer. Geophys. Union, 329-346.

- — - A. Goto, W. Ohfuchi, and S.-P. Xie, 2008: On the importance of midlatitude oceanic frontal zones for the mean state and dominant variability in the tropospheric circulation. Geophys. Res. Lett., 35, L15709, https://doi.org/10.1029/ 2008GL034010.

Nan, S., and J. Li, 2003: The relationship between the summer precipitation in the Yangtze River valley and the boreal spring Southern Hemisphere annular mode. Geophys. Res. Lett., 30, 2266, https://doi.org/10.1029/2003GL018381.

Nonaka, M., H. Nakamura, B. Taguchi, N. Komori, A. Kuwanoyoshida, and K. Takaya, 2009: Air-sea heat exchanges characteristic of a prominent midlatitude oceanic front in the South Indian Ocean as simulated in a high-resolution coupled GCM. J. Climate, 22, 6515-6535, https://doi.org/10.1175/ 2009JCLI2960.1.

Ogawa, F., H. Nakamura, K. Nishii, T. Miyasaka, and A. KuwanoYoshida, 2012: Dependence of the climatological axial latitudes of the tropospheric westerlies and storm tracks on the latitude of an extratropical oceanic front. Geophys. Res. Lett., 39, L05804, https://doi.org/10.1029/2011GL049922.

- — — - — - and —, 2016: Importance of midlatitude oceanic frontal zones for the annular mode variability: Interbasin differences in the southern annular mode signature. J. Climate, 29, 6179-6199, https://doi.org/10.1175/ JCLI-D-15-0885.1.

O'Reilly, C. H., and A. Czaja, 2015: The response of the Pacific storm track and atmospheric circulation to Kuroshio Extension variability. Quart. J. Roy. Meteor. Soc., 141, 52-66, https:// doi.org/10.1002/qj.2334. 
Palmén, E., and C. W. Newton, 1969: Atmospheric Circulation Systems: Their Structure and Physical Interpretation. Academic Press, 603 pp.

Peng, S., W. A. Robinson, and M. P. Hoerling, 1997: The modeled atmospheric response to midlatitude SST anomalies and its dependence on background circulation states. J. Climate, 10, 971-987, https://doi.org/10.1175/1520-0442(1997)010<0971: TMARTM $>2.0 . \mathrm{CO} ; 2$.

Qiu, B., S. Chen, N. Schneider, and B. Taguchi, 2014: A coupled decadal prediction of the dynamic state of the Kuroshio Extension system. J. Climate, 27, 1751-1764, https://doi.org/ 10.1175/JCLI-D-13-00318.1.

Rayner, N. A., D. E. Parker, E. B. Horton, C. K. Folland, L. V. Alexander, D. P. Rowell, E. C. Kent, and A. Kaplan, 2003: Global analyses of sea surface temperature, sea ice, and night marine air temperature since the late nineteenth century. J. Geophys. Res., 108, 4407, https://doi.org/10.1029/ 2002JD002670.

Révelard, A., C. Frankignoul, N. Sennechael, Y. O. Kwon, and B. Qiu, 2016: Influence of the decadal variability of the Kuroshio Extension on the atmospheric circulation in the cold season. J. Climate, 29, 2123-2144, https://doi.org/10.1175/ JCLI-D-15-0511.1.

Sampe, T., H. Nakamura, A. Goto, and W. Ohfuchi, 2010: Significance of a midlatitude SST frontal zone in the formation of a storm track and an eddy-driven westerly jet. J. Climate, $\mathbf{2 3}$, 1793-1814, https://doi.org/10.1175/2009JCLI3163.1.

Small, R. J., R. A. Tomas, and F. O. Bryan, 2014: Storm track response to ocean fronts in a global high-resolution climate model. Climate Dyn., 43, 805-828, https://doi.org/10.1007/ s00382-013-1980-9.
Smirnov, D., M. Newman, M. A. Alexander, Y. O. Kwon, and C. Frankignoul, 2015: Investigating the local atmospheric response to a realistic shift in the Oyashio sea surface temperature front. J. Climate, 28, 1126-1147, https://doi.org/10.1175/ JCLI-D-14-00285.1.

Taguchi, B., H. Nakamura, M. Nonaka, and S.-P. Xie, 2009: Influences of the Kuroshio/Oyashio Extensions on air-sea heat exchanges and storm-track activity as revealed in regional atmospheric model simulations for the 2003/04 cold season. J. Climate, 22, 6536-6560, https://doi.org/10.1175/ 2009JCLI2910.1.

,,,--- N. Komori, A. Kuwano-Yoshida, K. Takaya, and A. Goto, 2012: Seasonal evolutions of atmospheric response to decadal SST anomalies in the North Pacific subarctic frontal zone: Observations and a coupled model simulation. J. Climate, 25, 111-139, https://doi.org/10.1175/JCLI-D-11-00046.1.

Trenberth, K. E., 1986: An assessment of the impact of transient eddies on the zonal flow during a blocking episode using localized Eliassen-Palm flux diagnosis. J. Atmos. Sci., 43, 2070-2087, https://doi.org/10.1175/1520-0469(1986)043<2070: AAOTIO $>2.0 . \mathrm{CO} ; 2$.

1991: Storm tracks in the Southern Hemisphere. J. Atmos. Sci., 48, 2159-2178, https://doi.org/10.1175/15200469(1991)048<2159:STITSH > 2.0.CO;2.

_ , and J. M. Caron, 2001: Estimates of meridional atmosphere and ocean heat transports. J. Climate, 14, 3433-3443, https://doi.org/ 10.1175/1520-0442(2001)014<3433:EOMAAO > 2.0.CO;2.

—_, and D. P. Stepaniak, 2003: Covariability of components of poleward atmospheric energy transports on seasonal and interannual timescales. J. Climate, 16, 3691-3705, https://doi.org/ 10.1175/1520-0442(2003)016<3691:COCOPA > 2.0.CO;2. 